\title{
Demographic, Psychological, and Social Characteristics of Self-Identified Lesbian, Gay, and Bisexual Adults in a US Probability Sample
}

\author{
Gregory M. Herek • Aaron T. Norton • \\ Thomas J. Allen • Charles L. Sims \\ Published online: 3 March 2010 \\ (C) The Author(s) 2010. This article is published with open access at Springerlink.com
}

\begin{abstract}
Using data from a US national probability sample of self-identified lesbian, gay, and bisexual adults $(N=662)$, this article reports population parameter estimates for a variety of demographic, psychological, and social variables. Special emphasis is given to information with relevance to public policy and law. Compared with the US adult population, respondents were younger, more highly educated, and less likely to be non-Hispanic White, but differences were observed between gender and sexual orientation groups on all of these variables. Overall, respondents tended to be politically liberal, not highly religious, and supportive of marriage equality for same-sex couples. Women were more likely than men to be in a committed relationship. Virtually all coupled gay men and lesbians had a same-sex partner, whereas the vast majority of coupled bisexuals were in a heterosexual relationship. Compared with bisexuals, gay men and lesbians reported stronger commitment to a sexualminority identity, greater community identification and involvement, and more extensive disclosure of their sexual orientation to others. Most respondents reported experiencing little or no choice about their sexual orientation. The importance of distinguishing among lesbians, gay men, bisexual women, and bisexual men in behavioral and social research is discussed.
\end{abstract}

G. M. Herek $(\bowtie) \cdot$ A. T. Norton • T. J. Allen • C. L. Sims Psychology Department, University of California,

One Shields Avenue,

Davis, CA 95616-8686, USA

e-mail: gmherek@ucdavis.edu

A. T. Norton

e-mail: atnorton@ucdavis.edu

T. J. Allen

e-mail: tjallen@ucdavis.edu
Keywords Lesbians - Gay men · Bisexuals · Public policy · Sampling - Survey research · Committed relationships .

Politics and religion - Identity, community, and disclosure

"Empirical studies using nonrepresentative samples of gay men and lesbians show that the vast majority of participants have been involved in a committed relationship at some point in their lives [and] that large proportions are currently involved in such a relationship...." (American Psychological Association 2007, pp. 14-15)

“...[D]ata are not available to indicate the exact number of lesbian and gay parents in the United States...." (American Psychological Association 2007, p. 25)

"Most or many gay men and lesbians experience little or no choice about their sexual orientation." (American

Psychological Association 2003, p. 8)

These three passages, all excerpted from amicus briefs submitted jointly by the American Psychological Association (APA) and other professional organizations in court cases involving gay rights, illustrate some of the ways in which descriptive data about the lesbian, gay, and bisexual population are relevant to policy debates. In each instance, the APA and its co-amici summarized current knowledge about an aspect of the US gay, lesbian, and bisexual population that was relevant to a question being considered by the court-respectively, how many gay men and lesbians are involved in a committed relationship, how many are parents, and how many experience their sexual orientation as a choice. Yet, in each instance, the briefs could not provide definitive population estimates because relevant data were not available from nationally represen- 
tative samples of self-identified gay, lesbian, and bisexual adults.

The need for data describing the gay, lesbian, and bisexual population is not limited to legal proceedings. As Black et al. (2000) have noted, such data are relevant to a wide variety of policy debates in the USA, including those about initiatives designed to prohibit discrimination based on sexual orientation, public policy concerning the provision of benefits to same-sex couples, military policy concerning service by openly gay personnel, and lesbian and gay parental rights. They observed that "informed policy analysis about these issues requires accurate demographic information about the lesbian and gay population" (Black et al. 2000, p. 139).

Population data describing lesbians, gay men, and bisexuals also have important scientific implications insofar as they can inform researchers who study the gay, lesbian, and bisexual population. Examination of demographic, social, and psychological patterns in the population, for example, can highlight gaps in current scientific knowledge and suggest hypotheses for empirical testing. Reliable estimates of the extent to which various characteristics and experiences are present in the sexual-minority population can also assist researchers in interpreting data from nonprobability samples and assessing their likely generalizability.

To date, however, most social science knowledge about people who identify as gay, lesbian, or bisexual has been based on data from nonprobability samples. These samples have been recruited through such venues as clubs, cafes, and commercial establishments catering to gay men, lesbians, and bisexuals; neighborhood and community events; community-based organizations; local and national publications; e-mail lists and web-based communities; and friendship networks (e.g., Bell and Weinberg 1978; Bradford et al. 1994; Herek et al. 1999; Martin and Dean 1990; Riggle et al. 2005; Rothblum et al. 2004; Rothblum and Factor 2001). Researchers have also used public records to recruit specific groups, such as same-sex couples who have married or legally registered their partnership in states where they are allowed to do so (Balsam et al. 2008; Rothblum et al. 2008). Although the data collected from such samples are sources of important information, the extent to which their participants represent the larger population is unknown (Harry 1986; Meyer and Colten 1999; Sell and Petrulio 1996).

It has often been assumed that traditional probability sampling methods - which permit assessment of sampling error and whose results can be generalized beyond a specific sample - are not feasible with lesbians, gay men, and bisexuals because nonheterosexuals constitute only a small proportion of the population and because sexual stigma deters some individuals from disclosing their homosexual or bisexual orientation to researchers. Con- cerns about the limitations of findings from convenience samples, however, have fostered the development of innovative strategies for obtaining probability samples of gay, lesbian, and bisexual people (Cochran and Mays 2006; Meyer and Wilson 2009). For example, researchers have used various methods to identify nonheterosexuals in large national probability samples (Badgett 1995; Cochran and Mays 2006; Edelman 1993; Harry 1990; Laumann et al. 1994) and have applied probability sampling methods to specific settings or venues where sexual-minority individuals are known to be concentrated (Blair 1999; Diaz et al. 2004; Diaz et al. 1996; Stall and Wiley 1988).

When examining this body of research, it is important to note that sexual orientation is a multifaceted construct that encompasses sexual attraction, sexual behavior, personal identity, romantic relationships, and community membership (Herek 2000; Sell 2007). Most social and behavioral research has operationally defined sexual orientation in terms of attraction, behavior, or identity, or some combination of these constructs. Which of these definitions is most appropriate for a particular study depends on the research goals (Sell and Silenzio 2006). For example, studies of sexually transmitted diseases among men who have sex with men might optimally focus on sexual behavior, whereas research on experiences stemming from one's status as an openly gay, lesbian, or bisexual individual would, ideally, operationalize sexual orientation in terms of identity.

However, even in studies for which sexual orientation identity is the relevant variable, researchers employing existing data sets based on large probability samples have often had to operationalize sexual orientation in terms of sexual behavior simply because most surveys have not collected data about identity. In many studies of economic discrimination that use national survey data sets, for example, the results have been characterized in terms of disparities between heterosexual workers and their gay or lesbian counterparts (e.g., Badgett 1995; Berg and Lien 2002; Blandford 2003). Although the terms "heterosexual," "gay," and "lesbian" suggest a focus on identity, limitations of the available data dictated that the operational definitions of sexual orientation be based on self-reported sexual behavior, from which the researchers inferred respondents' sexual orientation identity.

Although unavoidable, such use of sexual behavior as a proxy for identity and community membership is limiting for several reasons (see Herek et al. 2007). For example, it inevitably excludes gay, lesbian, and bisexual individuals who were not sexually active during the specified time period (e.g., Carpenter 2005). Moreover, the population of individuals who have experienced same-sex attractions or engaged in same-sex sexual behavior includes many people who do not identify as lesbian, gay, or bisexual (e.g., Cochran and Mays 2006; Laumann et al. 1994). Insofar as 
much of the stigma directed at gay, lesbian, and bisexual people finds behavioral expression when others become aware of their sexual orientation identity (e.g., Herek 2009b), the experiences of self-identified gay, lesbian, and bisexual people are likely to differ in important respects from, say, self-identified heterosexuals with incidental same-sex attractions or sexual behavior.

Some studies with probability samples have operationalized sexual orientation in terms of identity, but they have been limited by small sample sizes. ${ }^{1}$ For example, the National Health and Social Life Survey collected data about respondents' sexual behavior, attractions, and sexual orientation identity. However, the sample ultimately included only 24 women who identified as lesbian or bisexual and only 39 men who identified as gay or bisexual (Laumann et al. 1994). Similarly, the National Survey of Midlife Development in the United States asked respondents to label their sexual orientation as heterosexual, homosexual, or bisexual. Of the approximately 3,000 respondents in this national probability sample, only 41 identified as homosexual and only 32 as bisexual (Mays and Cochran 2001). Such small numbers clearly preclude extensive analysis of self-identified lesbians, gay men, and bisexuals.

Other studies using probability samples have obtained larger numbers of self-identified lesbian, gay, and bisexual respondents, but the samples have been restricted to specific US states (Carpenter 2005) or cities (Blair 1999; Sell et al. 2007) or to gay neighborhoods or venues in specific cities (Diaz et al. 1996; Stall and Wiley 1988). These studies have yielded invaluable data, but their findings may not be generalizable beyond those settings.

Another important limitation is that the data from probability samples have generally not permitted separate analyses of self-identified lesbians, gay men, bisexual women, and bisexual men. As noted previously, some studies that directly assessed sexual orientation identity have yielded samples that were simply too small to permit separate analyses of subgroups (e.g., Laumann et al. 1994; Mays and Cochran 2001). In other studies, the sexual orientation question was not framed in a manner that permitted differentiation between bisexual and homosexual respondents. For example, exit polls conducted in conjunction with national elections have asked respondents to indicate

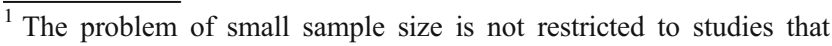
have focused on sexual orientation identity. For example, an analysis of data from male respondents in the third National Health and Nutrition Examination Survey Studies $(N=3,648)$ yielded a weighted total of 79 men who reported any same-sex sexual behavior during their lifetime (Cochran and Mays 2000). A 1985 ABC NewsWashington Post poll recruited a national probability sample of men and included a question about sexual attraction. Of the 663 respondents, 16 reported that they were attracted to members of their same sex and another five volunteered that they were attracted to both men and women (Harry 1990).
}

whether they are gay, lesbian, or bisexual without differentiating among these groups (Edelman 1993; Hertzog 1996).

Yet, empirical research with nonprobability samples suggests that important differences may exist among sexual-minority subgroups. For example, lesbians may differ from gay men in their likelihood of being involved in an intimate relationship (Peplau and Fingerhut 2007), bisexuals may differ from lesbians and gay men in the extent to which they are open about their sexual orientation and feel connected to a sexual-minority community (Balsam and Mohr 2007), and lesbians and bisexual women may differ from gay and bisexual men in the extent to which they manifest self-directed stigma (Balsam and Mohr 2007; Herek et al. 2009). Whether or not these findings can be generalized beyond the specific samples in which they were initially observed is as yet unknown, but they highlight the value of collecting data from probability samples that are sufficiently large to permit comparisons among gender and sexual orientation subgroups.

This article uses data from a national probability sample of self-identified gay, lesbian, and bisexual adults to estimate population parameters on a variety of demographic, psychological, and social variables. Recognizing that sexual orientation subgroups may differ, we also compare and contrast gay men, lesbians, bisexual men, and bisexual women on each variable. Rather than testing specific hypotheses, our central goal is to report basic descriptive data about self-identified gay, lesbian, and bisexual adults. Although an overwhelming number of questions about potentially interesting and important characteristics of the sexual-minority population could be generated, practical considerations limited the number of variables that could be assessed. Guided mainly by our review of policy studies and amicus briefs from scientific and professional organizations that have addressed topics for which data about the US population of self-identified gay, lesbian, and bisexual adults would be relevant (e.g., American Psychological Association 1986, 2003, 2007; Belkin 2008; Black et al. 2000; Egan and Sherrill 2005; Herek 2006; Schaffner and Senic 2006), we focused on variables in four categories.

First, we examined the basic demographic characteristics of this population, including age, educational background, and race and ethnicity. We also examined key variables identified by Black et al. (2000) as warranting description, including geographical distribution, household structure, and military veteran status.

Second, consistent with the present study's focus on adults who identify as gay, lesbian, or bisexual, we report descriptive data about key aspects of sexual orientation identity. These include the extent to which respondents used various identity labels in describing themselves; felt committed to their sexual orientation identity; had disclosed their sexual orientation to others; and were involved with 
the gay, lesbian, and bisexual community. We also assessed the extent to which respondents perceived they had chosen their sexual orientation, an issue that has often been raised in policy debates and in legal discussions of gay, lesbian, and bisexual rights (see, for example, the 2003 APA amicus brief quoted at the beginning of this article; see also Herman 1997).

Third, recognizing the importance of religious and political institutions in shaping contemporary policy and public opinion affecting gay, lesbian, and bisexual people, we assessed several aspects of respondents' religious and political involvement. Although it is widely recognized that the condemnation of homosexuality that characterizes many religious denominations often creates conflicts and challenges for gay, lesbian, and bisexual people, there has been relatively little examination of the role that religion plays in the lives of sexual-minority individuals (Rodriguez and Ouellette 2000). We obtained descriptive data concerning respondents' affiliation with a religious denomination, their participation in religious services, and the importance of religion in their daily lives. In the realm of political involvement, national exit poll data have suggested that lesbian, gay, and bisexual voters tend to be liberal and identify with the Democratic Party (e.g., Edelman 1993; Hertzog 1996). We assessed the extent to which these attributes characterize the larger lesbian, gay, and bisexual population.

Finally, relevant to ongoing national debates about marriage equality and lesbian and gay parenting (e.g., Herek 2006), we collected data concerning respondents' current relationship and parental status, as well as their future aspirations related to marrying. We also asked respondents about their general attitudes toward civil unions and marriage rights for same-sex couples. ${ }^{2}$

\section{Method}

The study employed a probability sample of Englishspeaking, self-identified lesbian, gay, and bisexual adults residing in the USA. The sample was drawn from the Knowledge Networks (KN) panel, a large (approximately 40,000 households at the time of data collection) probability sample of English-speaking US residents who were recruited through random digit dialing (RDD) methods. Upon initially joining the $\mathrm{KN}$ panel, respondents agreed to participate regularly in on-line surveys and were provided with free Internet access and equipment if they did not already have it. Thus, in contrast to Internet studies with volunteer samples recruited via the Web, the $\mathrm{KN}$ panel includes individuals who would not otherwise have Internet access because of their

\footnotetext{
$\overline{2}$ Data about hate crime victimization and related experiences among members of this sample are reported elsewhere (Herek 2009a).
}

financial or social situation. Reflecting this fact, $\mathrm{KN}$ samples more closely match the US population than do other Internet samples. Indeed, they are demographically similar to the RDD samples used in traditional telephone surveys (Chang and Krosnick 2009; see also Berrens et al. 2003) and have been used extensively in academic research (for examples, see Knowledge Networks 2009).

\section{Sample and Procedure}

All KN panel members routinely answer a battery of background questions, including one about their sexual orientation (“Are you yourself gay, lesbian, or bisexual?"). A probability sample of 902 English-speaking adults ( $\geq 18$ years of age) was drawn from the subset of all panel members who had previously responded affirmatively to this question. Following standard $\mathrm{KN}$ procedures, they each received an e-mail invitation to complete the survey at their convenience. A follow-up e-mail was sent to nonresponders after approximately 1 week. Neither invitation mentioned sexual orientation. As with all KN surveys, panel members were free to decline to participate.

A total of 775 individuals (86\%) accessed the questionnaire between September 13 and October 7, 2005. In response to an initial screening question (described subsequently), six respondents declined to state their sexual orientation, and 50 indicated they were heterosexual. ${ }^{3}$ They were thanked for their assistance, and their survey was terminated. This

\footnotetext{
${ }^{3}$ We hypothesized that these individuals were heterosexual respondents who had incorrectly characterized their sexual orientation on the original screening questionnaire (e.g., due to misunderstanding the question). However, we also recognized that some may have been gay, lesbian, or bisexual but reluctant to disclose this fact in the current questionnaire (e.g., out of concern that their responses might be seen by a household member who was unaware of their sexual orientation). We compared the personal characteristics of these respondents with those of the self-identified sexual-minority adults in the current sample. On most variables (including marital status, race and ethnicity, current employment status, residence in a metropolitan area, presence of children under 18 in their household, Internet access independent of $\mathrm{KN}$, political party affiliation, and self-described political ideology), the 50 respondents who reported they were heterosexual differed from the self-identified sexual-minority sample. Although we cannot draw definitive conclusions, these patterns are consistent with the hypothesis that most of the 50 respondents were indeed heterosexual. Moreover, insofar as educational level is correlated with general questionnaire response validity (e.g., Krosnick 1991), the fact that these respondents had less formal education than others $(42 \%$ had not attended college) is consistent with the hypothesis that many of them had misunderstood the original $\mathrm{KN}$ screening question. These analyses suggest that simply asking respondents whether they are "gay, lesbian, or bisexual"-with response options of "yes" and "no"- may not be an optimal strategy for ascertaining sexual orientation identity in national probability samples. The question on the current survey, which presented the different sexual orientations along a continuum and included the familiar term "straight" as a synonym for "heterosexual," may have been easier to comprehend and answer accurately.
} 
screening process left 719 self-identified lesbian, gay, and bisexual respondents who completed the questionnaire. Within that group, 56 households were represented by multiple respondents. In these cases, one respondent was randomly selected from the household for inclusion in the data set, yielding a final sample of 662. Taking into account all attrition in the $\mathrm{KN}$ panel since the earliest stage of RDD recruitment, the response rate for the present study was 30\% (American Association for Public Opinion Research 2006 [Formula 3]). This rate is relatively high for contemporary commercial surveys (Holbrook et al. 2008).

\section{Measures}

The variables included in the questionnaire are described here, and the wording of most questions is reported in the tables. When appropriate, the question wording was tailored to respondents' sexual orientation (bisexual vs homosexual) and gender.

Basic Demographic Characteristics and Other Background Variables Information about respondents' age, race and ethnicity, residence, location, and household composition had been routinely collected by Knowledge Networks in prior questionnaires. The present survey included a question asking whether the respondent was currently on active military duty, a member of the Military Reserves or National Guard, or a military veteran.

Sexual Orientation Identity As noted previously, all respondents had reported they were gay, lesbian, or bisexual on a previously administered $\mathrm{KN}$ questionnaire. The present survey began with a screening question that asked respondents "Which of the following best describes your sexual orientation?" and provided five options arrayed on a continuum from homosexual to heterosexual. For male respondents, the options were (a) gay or homosexual; (b) bisexual, mostly attracted to men; (c) bisexual, equally attracted to men and women; (d) bisexual, mostly attracted to women; (e) heterosexual or straight. For females, the first response option was lesbian, gay, or homosexual, and options (b) and (d) were transposed. Respondents were asked how often they use various identity terms to describe themselves ("Gay," "Lesbian" [women only], "Bisexual," "Queer," "Dyke" [women only], "Homosexual"). They were then asked to indicate their preferred term for characterizing their own sexual orientation (e.g., "Gay," "Lesbian," "Bisexual," "Queer," "Homosexual"). This label was subsequently inserted into questions that referred to the respondent's sexual orientation or identity. This individualized item wording is indicated throughout the present article as $[L / G / B / Q / H]$.

We used two measures to assess the strength of respondents' commitment to their sexual orientation identity and to the larger gay, lesbian, and bisexual community. First, three items assessing commitment to a sexual-minority identity were taken from the Internalized Homophobia Scale, or IHP (Herek et al. 1998; Herek et al. 2009): (1) "In general, I'm glad to be $[L / G / B / Q / H]$ "; (2) "If someone offered me the chance to be completely heterosexual ('straight'), I would accept the chance"; and (3) "I wish I weren't $[L / G / B / Q / H]$." Second, two items assessing community identification were adapted from the Importance to Identity subscale of the Collective Self-Esteem scale (Herek and Glunt 1995; Luhtanen and Crocker 1992): (1) "My membership in the $[L / G / B / Q / H]$ community is an important reflection of who I am" and (2) "Overall, my membership in the $[L / G / B / Q / H]$ community has very little to do with how I feel about myself." All of these items were presented with 5-point Likert-type response formats ranging from "strongly agree" to "strongly disagree," with each respondent's preferred identity label substituted for $[L / G / B / Q / H]$.

Perceived choice about one's sexual orientation was assessed with the question, "How much choice do you feel you had about being $[L / G / B / Q / H]$ ?" The response options were "no choice at all," "a small amount of choice," "a fair amount of choice," and "a great deal of choice."

Respondents were asked their age when they first knew about their sexual orientation ("How old were you when you first knew or decided you were [gay/lesbian/bisexual]?") and when they first disclosed it to another person ("How old were you the first time you told someone else that you are [gay/ lesbian/bisexual]?"). They were subsequently asked whether their mother or father knew about their sexual orientation and, if applicable, how many of their sisters and brothers knew about it. In addition, using a scale that ranged from 0 (not at all out to any of them) to 7 (completely out to all of them), respondents reported the extent to which they were "out of the closet (openly $[L / G / B / Q / H]$ )" to six additional groups: (1) "other relatives - not your immediate family," (2) "your current heterosexual ('straight') friends," (3) "your casual acquaintances who are heterosexual ('straight')," (4) "heterosexual ('straight') friends whom you knew before you came out," (5) "your boss and other supervisors at work," and (6) "the people you work with on a daily basis (other than your boss or supervisors)." A "doesn't apply to me" response option was included for each group.

Community involvement was assessed by asking respondents to "rate how important each of the following activities is to you these days. By important, we mean that you would feel differently about life and about yourself if you couldn't do this activity." The list of activities was adapted from a scale developed by Herek and Glunt (1995) and consisted of the following: (1) "Knowing what is going on in the local $[L / G / B / Q / H]$ community," (2) "Doing volunteer work in the $[L / G / B / Q / H]$ community," (3) "Giving money to $[L / G /$ $B / Q / H]$ organizations," (4) "Being politically active in the 
[L/G/B/Q/H] community," and (5) "Reading community newspapers and magazines for news about the $[L / G / B / Q / H]$ community." Each activity was rated on a 4-point scale (Not at all important, Somewhat important, Fairly important, Very important).

Respondents also were asked whether they had ever engaged in a variety of activities related to lesbian, gay, or bisexual issues, including public expressions of opinion ("Wore a button, posted a sign, or displayed a bumper sticker"); participating in a rally, march, or demonstration; contacting a government official; and contributing money to a lesbian, gay, or bisexual organization or cause. For comparison purposes, this series of questions was followed by a parallel set of items that asked whether the respondent had participated in the same activities for "a non-gay issue or cause - that is, something not related mainly to gay men, lesbians, or bisexuals."

Political and Religious Involvement Information about respondents' political party affiliation and ideology (liberal, moderate, conservative) had been previously collected by Knowledge Networks. For the present study, respondents were asked whether they had voted in the most recent (2004) presidential election and, if so, for which candidate. They were also asked for information about their religious denomination, frequency of attendance at religious services during the previous 12 months, how much guidance religion provides in their day-to-day living, and (for respondents who reported affiliation with a religious denomination and any attendance at religious services) the extent to which their congregation includes lesbian, gay, and bisexual members.

Relationships, Marriage, and Family Respondents were asked their current relationship status, their legal marital status, and how many children they have (including adopted children and stepchildren). Respondents currently in a relationship (including those who were married) were asked the gender of their partner. Those who were in a relationship but not married were asked whether they were cohabiting and the likelihood they would marry their partner if their state were to allow same-sex marriages (this conditional clause was omitted for respondents in Massachusetts, the only state where marrying a same-sex partner was legal at the time of data collection). Those who were not currently in a relationship were asked whether they would like to marry someday. Respondents' attitudes toward marriage rights for same-sex couples were assessed with three items. Using a 5-point Likert-type response format ranging from "strongly agree" to "strongly disagree," they indicated the extent to which they agreed or disagreed with each of the following statements: (1) "The law should allow two people of the same sex to marry each other." (2) "There is really no need to legalize same-sex marriage in the United States." (3) "The U.S. public isn't ready for a debate about gay marriage." In addition, respondents were asked whether they strongly supported, somewhat supported, somewhat opposed, or strongly opposed state laws to create civil unions. An accompanying note explained that "civil unions are not marriage, but give a same-sex couple some legal protection in their home state in areas such as inheritance, health insurance, and hospital visits."

\section{Data Analysis}

Tables $1,2,3,4,5,6,7$, and 8 report population parameter estimates with $95 \%$ confidence intervals (CIs). The CIs facilitate comparisons among the four gender and sexual orientation subgroups and are preferable to $p$ values because they indicate whether group differences are statistically significant while also providing additional information about effect size (Cumming 2008; Wilkinson and Task Force on Statistical Inference 1999).

As reported subsequently, the four subgroups differed significantly in age, race, and educational level. We conducted analyses to assess whether these demographic patterns might account for the group differences in the outcome variables reported in Tables 3, 4, 5, 6, 7, and 8. For each outcome variable, therefore, we conducted two linear regression analyses (for continuous and ordinal outcome variables) or two logistic regression analyses (for categorical outcome variables). In the first equation, sexual orientation (homosexual vs bisexual), gender, and their multiplicative interaction term were entered. In the second equation, age, educational level, and race (dichotomized as Black vs nonBlack) were added as statistical controls. Except where noted in the subsequent text, inclusion of the control variables did not alter the patterns of significant differences among subgroups shown in the tables.

\section{Weighting}

The KN panel's original RDD design yielded a simple random sample with equal probability of selection for all US households with a landline telephone. However, the actual probability of selection for individual respondents was affected by multiple factors (e.g., differences in household size, number of telephone lines). Design weights were assigned to each case to adjust for unequal probability of selection (e.g., Kish 1965). ${ }^{4}$ Because the use of weighted

\footnotetext{
${ }^{4}$ Design weights were computed to account for (a) variations in the number of adults and telephone lines in the household; (b) oversampling of Blacks and Hispanics, households with prior Internet access, and, early in the life of the KN panel, residents of California, New York, Florida, Texas, and Central regional states; (c) undersampling of telephone numbers for which matching addresses were unavailable and of households in areas without MSN-WebTV coverage; and (d) slight overrepresentation of Chicago and Los Angeles during KN's early pilot testing.
} 
data necessitates special analytic techniques to correct standard errors (Lee and Forthofer 2006), analyses were conducted using STATA and SPSS Complex Samples, which permit such correction.

\section{Results}

The sample consisted of 311 women (152 lesbians, 159 bisexuals) and 351 men (241 gay men, 110 bisexuals). Applying design weights, the weighted sample was $34.8 \%$ gay male, $14.6 \%$ lesbian, $26.9 \%$ bisexual male, and $23.7 \%$ bisexual female (Table 1). ${ }^{5}$ Unless otherwise indicated, the weighted data are used hereafter.

\section{Representativeness Check}

One challenge associated with evaluating the representativeness of a lesbian, gay, and bisexual probability sample is the general lack of comparison data from the population of self-identified sexual minorities. Even though the US Census does not collect information about individuals' sexual orientation, however, Census data are available for a subset of the sexual-minority population, namely, adults who report they are members of a cohabiting same-sex couple. Taking advantage of the fact that such individuals were able to identify themselves in the 2000 Census, we assessed the present sample's representativeness by comparing its members who were cohabiting with a same-sex partner to their counterparts in the Census data.

These comparisons are shown in Table 2, with the 2000 Census data corrected for misclassifications of some heterosexual couples due to miscodings of the partners' gender (Black et al. 2007). ${ }^{6}$ Except for mean age, the two groups do not differ significantly, as indicated by the overlapping 95\% CIs. These findings are consistent with the conclusion that, apart from being slightly older, the current sample was generally representative of self-identified lesbian, gay, and bisexual adults in the USA.

\footnotetext{
${ }^{5}$ Among bisexuals, 27\% (40 men, 33 women) reported they were mainly attracted to people of their same sex, 39\% (34 men, 71 women) were mainly attracted to the other sex, and 34\% (36 men, 55 women) were attracted equally to both sexes. Because of the large margin of error associated with groups of such small size, these three categories were combined for the analyses presented subsequently.

${ }^{6}$ We are grateful to Dr. Gary Gates (UCLA Williams Institute) for his kind assistance in this regard.
}

Age, Race, Ethnicity, and Education

As shown in Table 1, the mean age of respondents was $39{ }^{7}$ approximately two thirds were non-Hispanic White, and roughly one third had earned a college degree. Significant differences were observed in these variables among the sexual orientation and gender groups. Gay men $(M=$ 45 years) were significantly older than all other groups, and lesbians $(M=40$ years $)$ were significantly older than bisexual women ( $M=32$ years). Only $43 \%$ of bisexual men were non-Hispanic White, compared with more than $70 \%$ of other respondents ( $21 \%$ of bisexual men were Hispanic and $29 \%$ were non-Hispanic Black). More homosexuals than bisexuals had earned a bachelor's degree: $46 \%$ of gay men and $41 \%$ of lesbians reported having a degree, compared with only $16 \%$ of bisexual men and $28 \%$ of bisexual women.

According to Census data from approximately the same time period, the mean age of US adults (18 and older) was 45 , about $75 \%$ were non-Hispanic White, and $24 \%$ had earned a college degree. ${ }^{8}$ Thus, the present sample was younger than the US adult population, was less likely to be non-Hispanic White, and had a higher level of formal education. However, these patterns were not uniform across subgroups within the sample. Gay men's mean age was not significantly different from that of US adult men, whereas the other sexual orientation groups were significantly younger. Patterns of race and ethnicity among gay men and lesbians did not differ from the US population, but bisexual men were less likely to be non-Hispanic White, and bisexual women were less likely to be Hispanic or nonHispanic Black. ${ }^{9}$ Finally, whereas gay men and lesbians were significantly more likely than the US adult population to have earned a college degree, bisexual men and women did not differ significantly from the population in this regard.

\footnotetext{
${ }^{7}$ Approximately one third of the respondents (34\%) were under 30, $33 \%$ were $30-44$ years old, and $33 \%$ were 45 or older. Gay men were underrepresented in the 18-29 age category, compared with bisexual men and women; bisexual men were underrepresented in the 30-44 category, compared with gay men and lesbians; and bisexual women were underrepresented in the 45 and older category, compared with gay men and lesbians. However, because of the small number of respondents in some subcategories, these comparisons across sexual orientation subgroups must be considered tentative.

${ }^{8}$ Comparisons were made with data from the US Census Bureau's American Community Surveys 2000-2003, using the UC Berkeley SDA interface (http://sda.berkeley.edu/archive.htm).

${ }^{9}$ These patterns describe respondents who identified with a single racial or ethnic group. Our data do not permit intensive analyses of respondents reporting mixed race ancestry.
} 
Table 1 Demographic characteristics of sample

\begin{tabular}{|c|c|c|c|c|c|}
\hline Variable & Gay men & Lesbians & Bisexual men & Bisexual women & Total \\
\hline Unweighted $N$ & 241 & 152 & 110 & 159 & 662 \\
\hline Weighted \% & 34.8 & 14.6 & 26.9 & 23.7 & 100 \\
\hline CI & $28.9-41.2$ & $11.7-18.2$ & $19.1-36.4$ & $18.8-29.3$ & \\
\hline \multicolumn{6}{|l|}{ Age } \\
\hline Range & $23-89$ & $18-79$ & $18-40$ & $18-76$ & $18-89$ \\
\hline Mean & $45.3 \mathrm{a}$ & $40.1 \mathrm{~b}$ & $36.6 \mathrm{bc}$ & $31.8 \mathrm{c}$ & 39.0 \\
\hline $\mathrm{CI}$ & $43.0-47.5$ & $37.7-42.6$ & $32.0-41.1$ & $29.3-34.3$ & $37.1-40.9$ \\
\hline \multicolumn{6}{|l|}{ Race/Ethnicity } \\
\hline Non-Hispanic White & $70.5 \%$ ab & $74.4 \% \mathrm{a}$ & $43.0 \% \mathrm{~b}$ & $77.5 \% \mathrm{a}$ & $65.4 \%$ \\
\hline $\mathrm{CI}$ & $59.6-79.5$ & $62.6-83.5$ & $25.8-62.1$ & $65.9-86.0$ & $56.5-73.2$ \\
\hline Non-Hispanic Black & $14.0 \%$ & $12.8 \%$ & $28.6 \%$ & $5.2 \%$ & $15.6 \%$ \\
\hline $\mathrm{CI}$ & $7.6-24.3$ & $6.1-24.9$ & $10.9-56.8$ & $2.4-10.9$ & $9.1-25.5$ \\
\hline Hispanic & $11.3 \%$ & $10.5 \%$ & $20.6 \%$ & $6.2 \%$ & $12.5 \%$ \\
\hline $\mathrm{CI}$ & $6.1-20.0$ & $5.0-20.6$ & $7.2-46.6$ & $2.7-13.6$ & $7.4-20.2$ \\
\hline Other, mixed race & $4.2 \%$ & $2.3 \%$ & $7.8 \%$ & $11.1 \%$ & $6.5 \%$ \\
\hline CI & $1.0-16.1$ & $0.8-6.6$ & $3.2-17.7$ & $4.8-23.5$ & $3.8-11.0$ \\
\hline \multicolumn{6}{|l|}{ Education (highest level) } \\
\hline Less than high school & $5.6 \%$ & $7.8 \%$ & $8.0 \%$ & $8.9 \%$ & $7.3 \%$ \\
\hline CI & $2.2-13.5$ & $3.1-18.4$ & $3.1-19.4$ & $3.6-20.2$ & $4.6-11.6$ \\
\hline High school diploma & $19.5 \%$ & $17.5 \%$ & $47.2 \%$ & $26.8 \%$ & $28.4 \%$ \\
\hline $\mathrm{CI}$ & $12.6-29.1$ & $9.8-29.3$ & $27.1-68.3$ & $16.5-40.4$ & $20.7-37.6$ \\
\hline Some college ( $<4$ years) & $28.5 \%$ & $33.8 \%$ & $28.9 \%$ & $36.8 \%$ & $31.4 \%$ \\
\hline $\mathrm{CI}$ & $21.4-36.9$ & $25.3-43.5$ & $15.1-48.2$ & $27.1-47.8$ & $25.6-37.7$ \\
\hline Bachelor's degree or higher & $46.4 \%$ a & $40.9 \%$ ac & $15.9 \% \mathrm{~b}$ & $27.5 \% \mathrm{bc}$ & $32.9 \%$ \\
\hline $\mathrm{CI}$ & $37.5-55.4$ & $31.9-50.6$ & $9.1-26.1$ & $19.3-37.4$ & $27.5-38.8$ \\
\hline
\end{tabular}

Military service

Currently serving or veteran

CI

Never served

CI

Census region

Northeast

CI

South

CI
$15.1 \%$ a

9.8-22.5

$84.9 \%$ a

$77.5-90.2$
$10.6 \%$ a

5.5-19.4

$89.4 \%$ a

80.6-94.5
$20.8 \%$ a

11.4-34.8

$79.2 \%$ a

65.2-88.6
$0.7 \% \mathrm{~b}$

$0.1-5.1$

$99.3 \%$ b

94.9-99.9

$18.5 \%$

12.3-27.0

10.7-28.0

15.5-30.1

$37.7 \%$

$29.4-46.8$
$36.2 \%$

$26.8-46.8$
$27.6 \%$

$12.4-50.5$

$40.6 \%$

$21.3-63.4$
$35.1 \%$

23.9-48.2
$12.6 \%$

9.3-16.8

$87.4 \%$

83.2-90.7

$22.0 \%$

$16.3-29.0$

$37.7 \%$

$30.4-45.5$ 
Table 1 (continued)

\begin{tabular}{|c|c|c|c|c|c|}
\hline Variable & Gay men & Lesbians & Bisexual men & Bisexual women & Total \\
\hline Midwest & $11.9 \%$ & $22.9 \%$ & $17.1 \%$ & $16.5 \%$ & $16.0 \%$ \\
\hline CI & $7.8-17.8$ & $16.2-31.3$ & $8.8-30.4$ & $11.0-24.1$ & $12.5-20.2$ \\
\hline West & $28.4 \%$ & $23.2 \%$ & $14.7 \%$ & $29.9 \%$ & $24.3 \%$ \\
\hline $\mathrm{CI}$ & $20.4-38.2$ & $16.3-31.9$ & $7.6-26.6$ & $20.7-41.0$ & $19.5-29.9$ \\
\hline \multicolumn{6}{|l|}{ Type of residence area } \\
\hline Large city & $56.1 \%$ & $40.8 \%$ & $43.3 \%$ & $38.0 \%$ & $46.1 \%$ \\
\hline CI & $47.1-64.7$ & $31.1-51.2$ & $24.1-64.7$ & $27.7-49.5$ & $39.0-53.5$ \\
\hline Small city & $18.1 \%$ & $27.1 \%$ & $21.8 \%$ & $27.0 \%$ & $22.5 \%$ \\
\hline CI & $12.7-25.0$ & $19.0-37.2$ & $9.7-41.9$ & $18.4-37.6$ & $17.4-28.5$ \\
\hline Suburban & $17.5 \%$ & $16.7 \%$ & $22.2 \%$ & $18.6 \%$ & $18.9 \%$ \\
\hline CI & $11.7-25.2$ & $10.8-25.0$ & $8.5-46.6$ & $9.8-32.4$ & $13.3-26.2$ \\
\hline Rural or small town & $8.4 \%$ & $15.4 \%$ & $12.7 \%$ & $16.4 \%$ & $12.5 \%$ \\
\hline $\mathrm{CI}$ & $4.7-14.7$ & $9.9-23.1$ & $6.7-22.7$ & $10.1-25.7$ & $9.5-16.3$ \\
\hline
\end{tabular}

Housing

Homeowner
CI
Renter
CI
Doesn't pay for housing
CI

Household composition

1 adult (18 years or older)

CI

2 adults

CI

$3+$ Adults

CI

$\%$ with any children $(<18$ years $)$

CI
$56.4 \%$ a

46.9-65.4

$38.9 \%$ a

29.9-48.7

$4.8 \% \quad 5.0 \%$

2.3-9.7

2.2-11.1

$60.9 \%$ a

50.2-70.7

$30.8 \%$ b

18.2-47.0

$67.6 \%$ b

51.0-80.8

$1.6 \%$

0.4-5.7

$6.8 \%$

2.4-17.9

$40.3 \% \mathrm{ab}$

30.0-51.6

$52.8 \% \mathrm{ab}$

41.4-64.0

$49.2 \%$

42.0-56.5

$4.4 \%$

$2.7-7.3$

$46.4 \%$

$39.5-53.3$

$34.1 \%$ a

$0.4-5.7$
$30.1 \%$ ab

17.2-47.1

46.4-64.1

$32.3 \%$ a

25.0-40.5

$12.3 \%$

$7.2-20.3$

$4.8 \%$ a

2.0-10.9
$28.7 \%$ b

21.0-37.8

$54.0 \%$ b

44.0-63.8

$17.3 \%$

$10.5-27.2$

$16.6 \%$ a

$9.8-26.8$
$44.6 \% \mathrm{ab}$

$25.2 \%$

12.4-44.7

$25.6 \% \mathrm{ab}$

$10.0-51.5$
24.6-66.6
$21.8 \%$ b

15.0-30.5

$55.3 \%$ b

43.6-66.5

$22.9 \%$

13.1-37.0

$49.3 \%$ b

38.0-60.8
$36.7 \%$

$30.7-43.2$

$44.2 \%$

$37.0-51.8$

$19.0 \%$

$13.9-25.5$

$22.7 \%$

16.3-30.6

Within rows, values with different lowercase letters differ significantly, as indicated by nonoverlapping confidence intervals 
Table 2 Demographic characteristics of cohabiting same-sex couples: 2000 US Census data and current sample

\begin{tabular}{lll}
\hline Variable & US Census & Current sample \\
\hline Gender (\% female) & $49.3 \%(48.8-49.9)$ & $48 \%(39.1-56.9)$ \\
$\begin{array}{l}\text { Race/ethnicity } \\
\text { (\% non-Hispanic } \\
\text { White) }\end{array}$ & $77.4 \%(77.0-77.9)$ & $74.1 \%(63.7-82.4)$ \\
$\begin{array}{l}\text { Mean age (years) } \\
\begin{array}{l}\text { Education (\% with } \\
\text { college degree or } \\
\text { higher) }\end{array}\end{array}$ & $41.9 \%(41.3-42.4)$ & $48 \%(39.2-56.9)$ \\
$\begin{array}{l}\text { Employment status } \\
\text { (\% employed) }\end{array}$ & $79.2 \%(78.7-79.6)$ & $79.2 \%(70.7-85.7)$ \\
$\begin{array}{l}\text { Housing (\% } \\
\text { homeowner) }\end{array}$ & $61.8 \%(61.2-62.3)$ & $69.1 \%(59.5-77.2)$ \\
& & \\
$\begin{array}{l}\text { Military service } \\
(\% \text { veteran) }\end{array}$ & $12.0 \%(11.7-12.4)$ & $11.8 \%(6.9-19.4)$ \\
\hline
\end{tabular}

Table displays population parameter estimates and 95\% confidence intervals (CIs) for same-sex cohabiting couples in 2000 US Census and current sample. Census data are drawn from a combined sample of the $1 \%$ and $5 \%$ Public Use Micro Samples of the 2000 US Census by G. Gates (May 3, 2007, personal communication), based on Black et al. (2003)

\section{Residence Variables}

In terms of residence patterns, the sample generally matched the US population except that a disproportionately small number of respondents lived in the Midwest. Within the sample, the sexual orientation groups did not differ significantly in their geographic distribution or the extent to which they resided in urban, suburban, or rural settings (Table 1). Women were more likely than men to live in a household with another adult. Although higher proportions of homosexuals reported owning their home and more bisexuals reported renting, this difference was not significant when age, education, and race were statistically controlled.

\section{Military Service}

Approximately $15 \%$ of gay men and $11 \%$ of lesbians had a history of military service. Compared with the US adult population, gay men were significantly less likely to have served, compared with all adult males (approximately $25 \%$ of whom had served), whereas lesbians were significantly more likely to have a history of military service, compared with all adult females (approximately $2 \%$ of whom had served). By contrast, bisexual men and women did not differ significantly from the US population in their pattern of military service.

\section{Sexual Orientation Identity}

Identity Labels Table 3 reports the proportions of respondents in each subgroup who said they used various identity labels for themselves "all the time," "often," or "sometimes" (vs respondents who reported using the labels "rarely" or "never"). Nearly all homosexual men (93\%) called themselves "Gay" at least sometimes, as did $76 \%$ of lesbians, $19 \%$ of bisexual men, and $10 \%$ of bisexual women. The proportions of lesbians (73\%) and bisexual women (11\%) who used "Lesbian" as an identity label was about the same as the proportions using "Gay." Among bisexuals, $71 \%$ of men and $60 \%$ of women labeled themselves "Bisexual" at least sometimes. By contrast, "Bisexual" was rarely used as an identity label by gay men $(2 \%)$ or lesbians $(8 \%)$. "Queer" was used by relatively few respondents ( $12 \%$ overall), and "Dyke" was used as a selflabel by only $10 \%$ of women. "Homosexual" was used at least sometimes by more than one third of the gay men and lesbians, but by relatively few bisexuals. Only $4 \%$ of respondents reported never using any of the labels.

Identity Commitment and Community Identification IHP scores were computed by summing responses to the items and dividing by 3 (responses to the "glad to be $[\mathrm{L} / \mathrm{G} / \mathrm{B} / \mathrm{Q} /$ $\mathrm{H}]$ " item were reversed). This procedure yielded a scale score $(\alpha=0.82)$ that could range from 1 to 5 , with higher scores indicating more negative attitudes toward or greater psychological distancing from one's sexual-minority identity (Herek et al. 2009). ${ }^{10}$ As indicated by the relatively low overall IHP mean score (Table 3), respondents generally expressed positive feelings about their sexual orientation identity. Indeed, only $6 \%$ of respondents manifested a general pattern of agreement with statements expressing negative feelings about one's sexual orientation (i.e., scored 4 or greater). The greatest degree of identity distancing was observed among bisexual men, who scored significantly higher than lesbians but whose mean score was nevertheless below the hypothetical midpoint of the scale. ${ }^{11}$ The two items assessing community identification were not significantly intercorrelated $(r=-0.09)$ and thus were analyzed separately. As shown in Table 3, a majority of respondents agreed that their membership in the sexual-minority

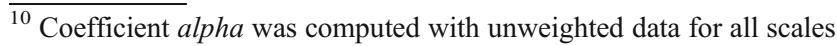
reported in this article.

${ }^{11}$ Because IHP scores were highly skewed, analyses were also conducted with a log-transformation of the scale scores. The pattern of results did not differ from the raw scores. Table 3 reports the more easily interpreted raw scores.
} 
Table 3 Identity characteristics

\begin{tabular}{|c|c|c|c|c|c|}
\hline Variable & Gay men & Lesbians & Bisexual men & Bisexual women & Total \\
\hline \multicolumn{6}{|c|}{$\begin{array}{l}\text { Self-labeling (\% using label "all the time," } \\
\text { "often," or "sometimes") }\end{array}$} \\
\hline “Gay” & $93.0 \% \mathrm{a}$ & $75.9 \% \mathrm{~b}$ & $18.7 \% \mathrm{c}$ & $9.5 \% \mathrm{c}$ & $50.7 \%$ \\
\hline $\mathrm{CI}$ & $87.7-96.1$ & $66.3-83.5$ & $10.2-31.6$ & $5.9-14.9$ & $43.5-58.0$ \\
\hline "Lesbian" & $\mathrm{N} / \mathrm{A}$ & $73.4 \%$ a & N/A & $11.2 \% \mathrm{~b}$ & $34.9 \%$ \\
\hline CI & & $64.2-80.9$ & & $7.0-17.5$ & $28.3-42.3$ \\
\hline "Bisexual" & $2.4 \%$ a & $7.6 \%$ a & $71.3 \% \mathrm{~b}$ & $60.3 \% \mathrm{~b}$ & $35.4 \%$ \\
\hline CI & $1.0-5.3$ & $3.7-14.9$ & $54.9-83.5$ & $49.0-70.7$ & $27.7-44.0$ \\
\hline “Queer” & $16.8 \%$ & $16.4 \%$ & $8.5 \%$ & $7.2 \%$ & $12.2 \%$ \\
\hline CI & $11.8-23.2$ & $10.4-24.8$ & $3.7-18.2$ & $2.7-17.5$ & $9.2-16.0$ \\
\hline "Homosexual" & $38.7 \%$ a & $35.9 \%$ a & $10.8 \% \mathrm{~b}$ & $3.7 \% \mathrm{~b}$ & $22.5 \%$ \\
\hline $\mathrm{CI}$ & $30.4-47.7$ & $27.0-45.9$ & $5.0-21.8$ & $1.8-7.4$ & $18.1-27.6$ \\
\hline "Dyke" & N/A & $16.9 \%$ & N/A & $6.0 \%$ & $10.1 \%$ \\
\hline $\mathrm{CI}$ & & $11.2-24.8$ & & $1.9-17.0$ & $6.3-16.1$ \\
\hline $\begin{array}{l}\text { Identity distancing (mean IHP; } \\
\text { higher score = greater distancing) }\end{array}$ & $1.97 \mathrm{ab}$ & $1.65 \mathrm{a}$ & $2.62 \mathrm{~b}$ & $1.84 \mathrm{ab}$ & 2.07 \\
\hline $\mathrm{CI}$ & $1.77-2.16$ & $1.49-1.82$ & $1.88-3.36$ & $1.63-2.06$ & $1.81-2.32$ \\
\hline
\end{tabular}

Community identification (\% strongly agree or agree somewhat)

"My membership in the $[L / G / B / Q / H]$
community is an important reflection
of who I am."

CI

"Overall, my membership in the

$[L / G / B / Q / H]$ community has very little to do with how I feel about myself."

CI

Perceived choice about sexual orientation

\begin{tabular}{|c|c|c|c|c|c|}
\hline No choice at all & $88.0 \%$ a & $68.4 \% \mathrm{~b}$ & $38.3 \% \mathrm{bc}$ & $40.6 \% \mathrm{c}$ & $60.6 \%$ \\
\hline $\mathrm{CI}$ & $80.6-92.8$ & $57.8-77.4$ & $21.8-57.9$ & $30.1-52.0$ & $52.6-68.1$ \\
\hline Small amount & $6.9 \%$ & $15.2 \%$ & $22.4 \%$ & $15.2 \%$ & $14.2 \%$ \\
\hline $\mathrm{CI}$ & $3.2-14.1$ & $9.6-23.3$ & $8.6-46.9$ & $9.6-23.1$ & $9.2-21.3$ \\
\hline Fair amount/Great deal & $5.2 \% \mathrm{a}$ & $16.4 \% \mathrm{ab}$ & $39.3 \% \mathrm{bc}$ & $44.3 \% \mathrm{c}$ & $25.2 \%$ \\
\hline $\mathrm{CI}$ & $2.6-9.9$ & $9.3-27.3$ & $20.6-61.9$ & $32.9-56.3$ & $18.4-33.5$ \\
\hline
\end{tabular}

Within rows, values with different lowercase letters differ significantly, as indicated by nonoverlapping confidence intervals. N/A=question not asked

$\begin{array}{lllll}44.6 \% \text { a } & 43.1 \% \mathrm{a} & 15.6 \% \mathrm{~b} & 24.7 \% \mathrm{ab} & 32.0 \% \\ 35.8-53.8 & 33.6-53.0 & 8.4-27.0 & 15.0-38.0 & 26.4-38.2 \\ 55.1 \% & 51.3 \% & 60.2 \% & 68.1 \% & 59.0 \% \\ 46.1-63.9 & 41.2-61.4 & 37.8-78.9 & 57.9-76.8 & 51.6-66.0\end{array}$

$46.1-63.9$

$41.2-61.4$

$37.8-78.9$

$57.9-76.8$

$1.6-66.0$ 
Table 4 Openness about sexual orientation

\begin{tabular}{|c|c|c|c|c|c|}
\hline Variable & Gay men & Lesbians & Bisexual men & Bisexual women & Total \\
\hline Mean age of self-identification & $15.1 \mathrm{a}$ & $18.0 \mathrm{~b}$ & $17.5 \mathrm{ab}$ & $19.9 \mathrm{~b}$ & 17.3 \\
\hline $\mathrm{CI}$ & $14.0-16.1$ & $16.5-19.5$ & $14.6-20.4$ & $18.5-21.4$ & $16.4-18.3$ \\
\hline Mean age of first disclosure & 20.2 & 21.1 & 21.5 & 21.0 & 20.9 \\
\hline $\mathrm{CI}$ & $19.2-21.2$ & $19.7-22.4$ & $18.6-24.4$ & $19.7-22.4$ & $20.0-21.7$ \\
\hline \multicolumn{6}{|l|}{ Out to: } \\
\hline Mother & $73.8 \% \mathrm{a}$ & $81.4 \% \mathrm{a}$ & $25.0 \% \mathrm{~b}$ & $35.4 \% \mathrm{~b}$ & $52.7 \%$ \\
\hline $\mathrm{CI}$ & $65.5-80.6$ & $73.0-87.7$ & $12.2-44.5$ & $25.9-46.2$ & $45.3-60.0$ \\
\hline Father & $60.1 \% \mathrm{a}$ & $58.0 \%$ a & $19.5 \% \mathrm{~b}$ & $22.2 \% \mathrm{~b}$ & $39.8 \%$ \\
\hline $\mathrm{CI}$ & $50.7-68.9$ & $47.6-67.8$ & $8.3-39.4$ & $15.2-31.2$ & $33.2-46.5$ \\
\hline Sister(s) (out to one or more) & $82.3 \% \mathrm{ab}$ & $87.4 \%$ a & $56.8 \%$ bc & $50.4 \% \mathrm{~cd}$ & $69.1 \%$ \\
\hline $\mathrm{CI}$ & $73.3-88.7$ & $78.2-93.0$ & $34.4-76.7$ & $36.8-63.9$ & $61.7-75.7$ \\
\hline Brother(s) (out to one or more) & $84.8 \%$ a & $81.5 \%$ a & $58.9 \% \mathrm{ab}$ & $39.1 \% \mathrm{~b}$ & $66.3 \%$ \\
\hline $\mathrm{CI}$ & $77.1-90.3$ & $70.7-89.0$ & $35.1-79.2$ & $27.4-52.2$ & $58.3-73.6$ \\
\hline \multicolumn{6}{|l|}{ Out to at least one: } \\
\hline Distant family member & $80.3 \%$ a & $83.2 \% \mathrm{a}$ & $27.6 \% \mathrm{~b}$ & $53.3 \% \mathrm{c}$ & $60.3 \%$ \\
\hline $\mathrm{CI}$ & $80.3-86.9$ & $83.2-89.3$ & $27.6-47.8$ & $53.3-64.6$ & $60.3-68.0$ \\
\hline Current heterosexual friend & $86.4 \% \mathrm{ab}$ & $94.2 \% \mathrm{a}$ & $69.2 \% \mathrm{~b}$ & $84.1 \% \mathrm{ab}$ & $82.6 \%$ \\
\hline $\mathrm{CI}$ & $79.3-91.4$ & $86.7-97.6$ & $51.6-82.6$ & $73.1-91.1$ & $77.4-86.7$ \\
\hline Casual heterosexual friend & $81.6 \% \mathrm{a}$ & $85.6 \%$ a & $49.9 \% \mathrm{~b}$ & $69.1 \% \mathrm{ab}$ & $70.9 \%$ \\
\hline $\mathrm{CI}$ & $74.1-87.3$ & $77.4-91.1$ & $29.2-70.7$ & $58.2-78.3$ & $63.0-77.7$ \\
\hline Prior heterosexual friend & $83.5 \%$ a & $89.5 \%$ a & $39.8 \% \mathrm{~b}$ & $79.8 \%$ a & $71.2 \%$ \\
\hline $\mathrm{CI}$ & $75.9-89.0$ & $81.3-94.3$ & $22.7-59.8$ & $68.8-87.6$ & $61.9-79.0$ \\
\hline Coworker & $80.8 \%$ a & $77.4 \% \mathrm{ab}$ & $18.1 \% \mathrm{c}$ & $56.0 \% \mathrm{~b}$ & $57.8 \%$ \\
\hline $\mathrm{CI}$ & $72.8-86.8$ & $67.5-85.0$ & $9.5-31.6$ & $43.7-67.5$ & $49.3-65.8$ \\
\hline Boss or supervisor & $72.8 \% \mathrm{a}$ & $71.2 \% \mathrm{ab}$ & $13.8 \% \mathrm{c}$ & $50.3 \% \mathrm{~b}$ & $50.9 \%$ \\
\hline $\mathrm{CI}$ & $63.7-80.4$ & $60.9-79.7$ & $7.0-25.4$ & $38.0-62.6$ & $43.0-58.8$ \\
\hline \multicolumn{6}{|l|}{ Mean Summary Score. Extent of outness to: } \\
\hline Extended family, heterosexual friends, and acquaintances & $5.40 \mathrm{ac}$ & $5.73 \mathrm{a}$ & $2.52 \mathrm{~b}$ & $4.45 \mathrm{c}$ & 4.46 \\
\hline $\mathrm{CI}$ & $4.94-5.86$ & $5.29-6.17$ & $2.12-2.92$ & $3.81-5.08$ & $4.10-4.83$ \\
\hline Coworkers and supervisors & $5.20 \mathrm{a}$ & $4.98 \mathrm{a}$ & $1.78 \mathrm{~b}$ & $3.36 \mathrm{c}$ & 3.80 \\
\hline $\mathrm{CI}$ & $4.64-5.76$ & $4.37-5.58$ & $1.23-2.33$ & $2.52-4.20$ & $3.33-4.27$ \\
\hline
\end{tabular}

Within rows, values with different lowercase letters differ significantly, as indicated by nonoverlapping confidence intervals. Questions about outness to parents were worded to reflect whether each parent was living or deceased. Questions about outness to siblings were asked only if respondents reported that they had one or more sisters or brothers 
Table 5 Community involvement and activism

\begin{tabular}{|c|c|c|c|c|c|}
\hline Variable & Gay men & Lesbians & Bisexual men & Bisexual women & Total \\
\hline \multicolumn{6}{|c|}{ Importance of community involvement (\% responding "very important" or "fairly important") } \\
\hline Knowing what is going on & $57.4 \%$ a & $47.3 \% \mathrm{a}$ & $29.0 \% \mathrm{ab}$ & $15.7 \% \mathrm{~b}$ & $38.4 \%$ \\
\hline $\mathrm{CI}$ & $48.2-66.1$ & $37.4-57.4$ & $12.1-54.8$ & $9.4-25.3$ & $31.4-45.9$ \\
\hline Doing community volunteer work & $29.4 \%$ a & $29.0 \%$ a & $10.7 \% \mathrm{ab}$ & $12.2 \% \mathrm{~b}$ & $20.3 \%$ \\
\hline $\mathrm{CI}$ & $22.0-38.0$ & $20.8-38.8$ & $4.8-22.1$ & $7.2-20.0$ & $16.1-25.2$ \\
\hline Giving money to organizations & $43.1 \%$ a & $33.9 \%$ a & $6.5 \% \mathrm{~b}$ & $7.8 \% \mathrm{~b}$ & $23.5 \%$ \\
\hline $\mathrm{CI}$ & $34.3-52.3$ & $25.2-43.8$ & $3.0-13.6$ & $4.5-13.0$ & $19.0-28.6$ \\
\hline Being politically active & $33.4 \%$ a & $36.2 \% \mathrm{a}$ & $8.4 \% \mathrm{~b}$ & $13.4 \% \mathrm{~b}$ & $22.3 \%$ \\
\hline $\mathrm{CI}$ & $25.5-42.4$ & $27.2-46.3$ & $3.8-17.4$ & $8.1-21.5$ & $18.0-27.4$ \\
\hline Reading newspapers and magazines & $56.0 \%$ a & $51.6 \% \mathrm{a}$ & $31.3 \% \mathrm{ab}$ & $19.4 \% \mathrm{~b}$ & $40.0 \%$ \\
\hline $\mathrm{CI}$ & $46.5-65.0$ & $41.5-61.6$ & $13.9-56.2$ & $12.1-29.6$ & $33.1-47.4$ \\
\hline \multicolumn{6}{|c|}{ Community activism (\% reporting having ever done this related to a sexual minority issue) } \\
\hline Button, sign, bumper sticker & $43.6 \% \mathrm{ab}$ & $58.1 \% \mathrm{a}$ & $23.5 \% \mathrm{~b}$ & $41.7 \% \mathrm{ab}$ & $39.9 \%$ \\
\hline $\mathrm{CI}$ & $35.0-52.7$ & $47.6-67.9$ & $11.2-42.8$ & $30.6-53.7$ & $33.4-46.7$ \\
\hline Rally, march, or demonstration & $49.4 \%$ a & $44.4 \% \mathrm{ab}$ & $25.3 \% \mathrm{ab}$ & $27.9 \% \mathrm{~b}$ & $37.0 \%$ \\
\hline $\mathrm{CI}$ & $40.3-58.5$ & $34.8-54.4$ & $12.5-44.6$ & $19.7-38.1$ & $30.9-43.7$ \\
\hline Contacting a government official & $42.3 \%$ a & $39.1 \% \mathrm{a}$ & $24.7 \% \mathrm{ab}$ & $20.2 \% \mathrm{~b}$ & $31.9 \%$ \\
\hline $\mathrm{CI}$ & $33.8-51.3$ & $30.3-48.7$ & $11.7-44.8$ & $13.2-29.7$ & $26.1-38.3$ \\
\hline Contributing money & $65.3 \%$ a & $53.3 \% \mathrm{ab}$ & $28.0 \% \mathrm{bc}$ & $24.6 \% \mathrm{c}$ & $43.9 \%$ \\
\hline $\mathrm{CI}$ & $56.1-73.5$ & $43.0-63.4$ & $14.6-47.0$ & $16.8-34.5$ & $37.1-50.8$ \\
\hline
\end{tabular}

Within rows, values with different lowercase letters differ significantly, as indicated by nonoverlapping confidence intervals

community had little to do with how they felt about themselves, and fewer than half considered their community membership to be an important reflection of themselves. These patterns were different across subgroups, however, with lesbians and gay men indicating stronger identification with the sexual-minority community than bisexuals (Table 3 ).

Choice about Sexual Orientation Overall, respondents reported that they did not experience their sexual orientation as a choice. This pattern varied somewhat, however, according to gender and sexual orientation. The vast majority of gay men $(88 \%)$ and roughly two thirds of lesbians $(68 \%)$ reported having had no choice at all about their sexual orientation. Combining respondents who said they'd had a small amount of choice with those reporting no choice, $95 \%$ of gay men and $84 \%$ of lesbians could be characterized as perceiving that they had little or no choice about their sexual orientation. More bisexuals than homosexuals reported having had a fair amount or great deal of choice about their sexual orientation. Nevertheless, fewer than half of the bisexuals ( $39 \%$ of men, $44 \%$ of women) endorsed either of the latter response options.

Disclosure of Sexual Orientation On average, respondents reported having first recognized their own sexual orientation when they were 17 years old (Table 4). Gay men said they first knew or decided they were gay at age 15 , which was significantly younger than for lesbians (18 years) or bisexual women (20 years). Bisexual men reported that they recognized their bisexuality at 17.5 years. On average, all groups 
Table 6 Religious characteristics of sample

\begin{tabular}{|c|c|c|c|c|c|}
\hline Variable & Gay men & Lesbians & Bisexual men & Bisexual women & Total \\
\hline \multicolumn{6}{|l|}{ Religious denomination } \\
\hline Protestant/other Christian: not Born Again & $31.6 \%$ & $36.6 \%$ & $29.9 \%$ & $22.6 \%$ & $29.7 \%$ \\
\hline $\mathrm{CI}$ & $(23.5-41.0)$ & $(27.6-46.6)$ & $(15.5-49.8)$ & $(15.7-31.4)$ & $(24.0-36.2)$ \\
\hline Born Again Christian & $15.9 \%$ & $14.8 \%$ & $22.1 \%$ & $16.3 \%$ & $17.5 \%$ \\
\hline $\mathrm{CI}$ & $(10.6-23.1)$ & $(8.2-25.3)$ & $(6.6-53.3)$ & $(7.6-31.5)$ & $(11.1-26.3)$ \\
\hline Catholic & $21.8 \%$ & $16.4 \%$ & $26.3 \%$ & $11.2 \%$ & $19.7 \%$ \\
\hline $\mathrm{CI}$ & $(15.3-30.2)$ & $(9.9-25.9)$ & $(11.1-50.5)$ & $(6.3-19.3)$ & $(14.0-26.8)$ \\
\hline Jewish & $0.4 \%$ & $1.9 \%$ & $0.5 \%$ & $2.4 \%$ & $1.2 \%$ \\
\hline $\mathrm{CI}$ & $(0.1-3.0)$ & $(0.8-4.9)$ & $(0.1-2.3)$ & $(0.8-6.8)$ & $(0.6-2.2)$ \\
\hline Wiccan, pagan & $1.5 \%$ & $4.5 \%$ & $1.5 \%$ & $6.6 \%$ & $3.1 \%$ \\
\hline $\mathrm{CI}$ & $(0.4-5.3)$ & $(2.1-9.4)$ & $(0.4-5.2)$ & $(3.4-12.4)$ & $(2.0-5.0)$ \\
\hline Buddhist & $0.4 \%$ & $1.1 \%$ & $3.4 \%$ & $5.8 \%$ & $2.6 \%$ \\
\hline $\mathrm{CI}$ & $(0.1-2.6)$ & $(0.3-3.8)$ & $(0.5-20.8)$ & $(2.3-13.7)$ & $(1.1-5.9)$ \\
\hline Atheist, agnostic, none & $26.7 \%$ & $21.4 \%$ & $16.3 \%$ & $30.7 \%$ & $24.2 \%$ \\
\hline $\mathrm{CI}$ & $(19.4-35.7)$ & $(14.2-31.1)$ & $(8.2-29.9)$ & $(21.0-42.5)$ & $(19.3-29.8)$ \\
\hline \multicolumn{6}{|l|}{ Attendance at religious services (past 12 months) } \\
\hline Weekly or more & $7.2 \%$ & $8.9 \%$ & $24.0 \%$ & $7.5 \%$ & $12.0 \%$ \\
\hline $\mathrm{CI}$ & $(4.0-12.6)$ & $(4.9-15.6)$ & $(8.3-52.6)$ & $(3.4-15.8)$ & $(6.5-21.2)$ \\
\hline Less than weekly but at least monthly & $13.9 \%$ & $7.9 \%$ & $12.7 \%$ & $7.9 \%$ & $11.3 \%$ \\
\hline CI & $(8.1-22.7)$ & $(4.2-14.4)$ & $(4.0-33.8)$ & $(4.1-14.5)$ & $(7.3-16.9)$ \\
\hline Once or a few times & $39.3 \%$ & $48.6 \%$ & $30.8 \%$ & $44.1 \%$ & $39.5 \%$ \\
\hline CI & $(30.9-48.4)$ & $(38.7-58.6)$ & $(14.9-53.1)$ & $(32.8-56.0)$ & $(32.8-46.7)$ \\
\hline Never & $39.7 \%$ & $34.6 \%$ & $32.5 \%$ & $40.5 \%$ & $37.2 \%$ \\
\hline $\mathrm{CI}$ & $(31.1-48.9)$ & $(25.0-45.6)$ & $(18.8-50.1)$ & $(30.1-51.8)$ & $(31.1-43.8)$ \\
\hline
\end{tabular}

Type of congregation

$$
\text { All or mostly heterosexual }
$$$$
\text { CI }
$$

At least half sexual minority

CI

Not applicable

CI

$\begin{array}{ccccc}35.2 \% & 36.5 \% & 43.9 \% & 30.8 \% & 36.7 \% \\ (27.0-44.3) & (27.9-46.2) & (24.9-64.8) & (22.1-41.2) & (30.0-44.0) \\ & & & & \\ 12.0 \% & 16.5 \% & 19.3 \% & 12.3 \% & 14.7 \% \\ (6.7-20.5) & (10.1-25.8) & (4.9-52.4) & (4.5-29.1) & (8.6-24.0) \\ 52.8 \% & & & & \\ (43.6-61.8) & (37.0-57.2) & (21.7-55.1) & (45.0-68.0) & (41.5-55.8)\end{array}$


Table 6 (continued)

\begin{tabular}{|c|c|c|c|c|c|}
\hline Variable & Gay men & Lesbians & Bisexual men & Bisexual women & Total \\
\hline \multicolumn{6}{|c|}{ Amount of daily guidance from religion } \\
\hline None at all & $33.4 \%$ & $26.7 \%$ & $16.7 \%$ & $35.0 \%$ & $28.3 \%$ \\
\hline $\mathrm{CI}$ & $(25.5-42.4)$ & $(18.3-37.1)$ & $(9.0-28.9)$ & $(25.1-46.2)$ & $(23.2-34.1)$ \\
\hline Some & $44.5 \%$ & $42.1 \%$ & $44.9 \%$ & $42.8 \%$ & $43.9 \%$ \\
\hline $\mathrm{CI}$ & $(35.6-53.9)$ & $(32.7-52.1)$ & $(25.8-65.7)$ & $(32.1-54.1)$ & $(36.8-51.1)$ \\
\hline Quite a bit & $15.0 \%$ & $14.1 \%$ & $17.6 \%$ & $12.7 \%$ & $15.0 \%$ \\
\hline $\mathrm{CI}$ & $10.0-21.7$ & $8.7-22.0$ & $8.7-32.3$ & $5.1-28.3$ & $11.0-20.2$ \\
\hline A great deal & $7.1 \%$ & $17.1 \%$ & $20.8 \%$ & $9.5 \%$ & $12.8 \%$ \\
\hline $\mathrm{CI}$ & $3.9-12.4$ & $10.3-27.1$ & $6.0-51.8$ & $5.3-16.5$ & $7.2-21.7$ \\
\hline Mean score & 1.96 & 2.22 & 2.42 & 1.97 & 2.12 \\
\hline $\mathrm{CI}$ & $1.8-2.1$ & $2.0-2.4$ & $1.9-2.9$ & $1.8-2.2$ & $2.0-2.3$ \\
\hline
\end{tabular}

reported having first told someone else about their sexual orientation when they were in their early 20s (Table 4). However, the regression analysis revealed differences among the subgroups. With age, education, and race entered in the equation, the effect of age was significant $(b=0.26[\mathrm{CI}=0.18$, $0.34], t(643)=6.50, p<0.001)$, and the parameter estimates became significant for both sexual orientation $(b=2.40$ [CI= $0.69,4.10], t(643)=2.76, p<0.01)$ and gender $(b=-2.30[\mathrm{CI}$ $=-3.93,-0.66], t(643)=-2.76, p<0.01)$. Thus, older respondents were likely to have first disclosed their sexual orientation at a later age than younger respondents. When this generational difference was statistically controlled, bisexuals and women tended to have first disclosed at a later age than, respectively, homosexuals and men.

Regarding respondents' outness within their immediate families, Table 4 indicates that their fathers were the least likely to know about their sexual orientation, whereas their sisters were the most likely to know. Gay men and lesbians were substantially more open about their sexual orientation with their parents and siblings than were bisexuals. For example, they were about three times as likely as bisexual men, and at least twice as likely as bisexual women, to be out to their mother.

Similar patterns were observed for outness to relatives outside one's immediate family, heterosexual friends and acquaintances, and workplace contacts (Table 4). The four items assessing openness to distant family members and heterosexual friends and acquaintances were recoded as a continuum ranging from 1 to 8 , summed, and divided by the number of items. The resulting scale scores $(\alpha=0.91)$ can range from 1 (not at all out) to 8 (completely out). The same procedure was followed with the two items about outness in the workplace $(\alpha=0.95)$. On average, respondents scored at the midpoint for outness to extended family and heterosexual friends and acquaintances, and slightly lower for outness to coworkers and supervisors. Comparisons of summary scores revealed that lesbians and gay men were more out to their relatives and heterosexual acquaintances and in the workplace than were bisexuals, especially bisexual men.

With the demographic control variables included in the regression equation, the unstandardized parameter estimates for workplace outness remained significant for sexual orientation but not for gender. Instead, the parameter for race became significant $(b=1.10[\mathrm{CI}=0.28,1.92], t(568)=2.63$, $p<0.001)$, indicating that Black respondents were less open about their sexual orientation in the workplace than were others. With this effect statistically controlled, bisexual men were still significantly less open in the workplace than other groups, as indicated by the significant parameter estimate for the gender $\times$ sexual orientation interaction $(b=-1.52$ $[\mathrm{CI}=-2.84,-0.19], t(568)=-2.25, p<0.05)$.

Community Involvement and Activism As shown in Table 5, fewer than half of the respondents attached a high level of importance to any of the aspects of community involvement included in the questionnaire. The greatest importance was accorded to obtaining information about the community ("knowing what is going on" and "reading newspapers or magazines"). Gay men and lesbians placed more importance on each of the five types of community involvement than did bisexual men and women. By summing responses and dividing by the total number of items, scale scores were 
Table 7 Political characteristics of sample

\begin{tabular}{|c|c|c|c|c|c|}
\hline Variable & Gay men & Lesbians & Bisexual men & Bisexual women & Total \\
\hline \multicolumn{6}{|l|}{ Party affiliation } \\
\hline Democrat & $82.0 \%$ & $81.7 \%$ & $60.5 \%$ & $76.0 \%$ & $74.7 \%$ \\
\hline $\mathrm{CI}$ & $(74.6-87.6)$ & $(71.3-88.9)$ & $(38.1-79.3)$ & $(65.5-84.0)$ & $(66.7-81.3)$ \\
\hline Republican & $13.1 \%$ & $16.7 \%$ & $29.8 \%$ & $17.3 \%$ & $19.2 \%$ \\
\hline $\mathrm{CI}$ & $(8.7-19.3)$ & $(9.8-27.1)$ & $(12.8-55.2)$ & $(10.4-27.5)$ & $(13.0-27.4)$ \\
\hline Other & $4.9 \%$ & $1.6 \%$ & $9.6 \%$ & $6.7 \%$ & $6.1 \%$ \\
\hline $\mathrm{CI}$ & $(2.0-11.3)$ & $(0.3-7.1)$ & $(3.5-23.8)$ & $(3.4-12.6)$ & $(3.7-10.0)$ \\
\hline \multicolumn{6}{|l|}{ Political ideology } \\
\hline Liberal & $62.9 \%$ & $66.0 \%$ & $45.3 \%$ & $53.0 \%$ & $56.4 \%$ \\
\hline $\mathrm{CI}$ & $53.1-71.8$ & $55.4-75.2$ & $25.7-66.4$ & $41.1-64.5$ & $48.6-63.8$ \\
\hline Moderate & $27.4 \%$ & $24.5 \%$ & $27.5 \%$ & $33.4 \%$ & $28.4 \%$ \\
\hline $\mathrm{CI}$ & $19.2-37.5$ & $16.8-34.3$ & $13.6-47.6$ & $22.5-46.5$ & $22.4-35.4$ \\
\hline Conservative & $9.7 \%$ & $9.5 \%$ & $27.2 \%$ & $13.6 \%$ & $15.2 \%$ \\
\hline $\mathrm{CI}$ & $5.7-15.9$ & $4.4-19.3$ & $10.1-55.6$ & $7.5-23.6$ & $9.1-24.3$ \\
\hline$\%$ Voted in 2004 & $88.8 \%$ & $83.6 \%$ & $86.1 \%$ & $83.4 \%$ & $86.2 \%$ \\
\hline $\mathrm{CI}$ & $(79.9-94.1)$ & (71.3-91.2) & (71.4-93.9) & (71.9-90.8) & $(80.8-90.2)$ \\
\hline \multicolumn{6}{|l|}{ Candidate voted for } \\
\hline John Kerry & $86.2 \%$ & $91.5 \%$ & $81.9 \%$ & $79.6 \%$ & $84.4 \%$ \\
\hline $\mathrm{CI}$ & $(79.5-91.0)$ & $(84.5-95.5)$ & $(66.5-91.1)$ & $(69.9-86.8)$ & $(79.6-88.3)$ \\
\hline George W. Bush & $11.7 \%$ & $7.6 \%$ & $9.9 \%$ & $15.0 \%$ & $11.2 \%$ \\
\hline $\mathrm{CI}$ & $(7.4-18.0)$ & $(3.9-14.3)$ & $(5.0-18.6)$ & $(9.4-23.1)$ & $(8.4-14.8)$ \\
\hline Ralph Nader & $1.4 \% \mathrm{a}$ & $0 \mathrm{~b}$ & $7.1 \% \mathrm{a}$ & $2.9 \% \mathrm{a}$ & $3.2 \%$ \\
\hline $\mathrm{CI}$ & $(0.3-5.9)$ & & $(1.9-23.4)$ & $(0.7-11.2)$ & $(1.3-7.6)$ \\
\hline
\end{tabular}

Within rows, values with different lowercase letters differ significantly, as indicated by nonoverlapping confidence intervals (engaged in all activities; not shown in Table 5). Gay men reported community activism in significantly more areas $(M=1.97, \mathrm{CI}=1.71-2.29)$ than did bisexual men $(M=1.01, \mathrm{CI}=0.38-1.65)$ or bisexual women $(M=1.13$, $\mathrm{CI}=0.83-1.44)$. Lesbians also reported activism in more areas $(M=1.94, \mathrm{CI}=1.63-2.26)$ than bisexuals, but their CI slightly overlapped with that of bisexual men. When the parallel questions about activism that was unrelated to sexual-minority issues were combined to create a summary score, a similar pattern emerged. As with sexual-minority activism, bisexuals reported a lower level of general activism than gay men and lesbians, although only the difference between gay men $(M=2.13, \mathrm{CI}=1.86-2.40)$ ranging from 0 (did not engage in any of the activities) to 4 
Table 8 Relationship and family characteristics

\begin{tabular}{|c|c|c|c|c|c|}
\hline Variable & Gay men & Lesbians & Bisexual men & Bisexual women $^{\mathrm{a}}$ & Total \\
\hline \multicolumn{6}{|l|}{ Current relationship status } \\
\hline \multicolumn{6}{|l|}{ In a same-sex relationship } \\
\hline Married, civil union, domestic partner & $4.1 \% \mathrm{a}$ & $16.1 \% \mathrm{~b}$ & $0.2 \% \mathrm{c}$ & $1.5 \%$ ac & $4.2 \%$ \\
\hline $\mathrm{CI}$ & $2.3-7.4$ & $9.8-25.2$ & $0-1.7$ & $0.5-4.3$ & $2.9-6.1$ \\
\hline Cohabiting $^{\mathrm{b}}$ & $24.9 \%$ a & $45.3 \% \mathrm{~b}$ & $3.0 \% \mathrm{c}$ & $3.3 \% \mathrm{c}$ & $16.9 \%$ \\
\hline CI & $18.5-32.6$ & $35.5-55.4$ & $0.9-9.5$ & $1.3-8.2$ & $13.5-21.0$ \\
\hline Not cohabiting & $10.7 \% \mathrm{ab}$ & $14.5 \%$ a & $2.1 \% \mathrm{ab}$ & $2.8 \% \mathrm{~b}$ & $7.1 \%$ \\
\hline $\mathrm{CI}$ & $6.7-16.6$ & $8.1-24.7$ & $0.5-8.8$ & $1.1-7.2$ & $5.0-10.0$ \\
\hline
\end{tabular}

In a different-sex relationship

\begin{tabular}{|c|c|c|c|c|c|}
\hline Currently married & $0.3 \% \mathrm{a}$ & $0 \mathrm{a}$ & $29.2 \% \mathrm{~b}$ & $45.2 \% \mathrm{~b}$ & $18.6 \%$ \\
\hline $\mathrm{CI}$ & $0.1-1.1$ & & $13.8-51.5$ & $34.3-56.6$ & $13.2-25.7$ \\
\hline Cohabiting, not married & $0 \mathrm{a}$ & $0 \mathrm{a}$ & $0.8 \% \mathrm{~b}$ & $16.3 \% \mathrm{c}$ & $4.1 \%$ \\
\hline $\mathrm{CI}$ & & & $0.2-3.7$ & $7.7-31.2$ & $1.9-8.6$ \\
\hline Not cohabiting & $0 \mathrm{a}$ & $0 \mathrm{a}$ & $7.9 \% \mathrm{~b}$ & $7.0 \% \mathrm{~b}$ & $3.8 \%$ \\
\hline $\mathrm{CI}$ & & & $3.2-18.3$ & $3.3-14.4$ & $2.1-6.7$ \\
\hline Not in a committed relationship ${ }^{c}$ & $60.0 \% \mathrm{a}$ & $24.2 \% \mathrm{~b}$ & $56.7 \%$ a & $23.3 \% \mathrm{~b}$ & $45.2 \%$ \\
\hline $\mathrm{CI}$ & $51.3-68.1$ & $16.9-33.2$ & $36.2-75.2$ & $15.3-33.8$ & $37.9-52.7$ \\
\hline
\end{tabular}

Would like to marry someday? (respondents not currently in a relationship)

\begin{tabular}{|c|c|c|c|c|c|}
\hline Yes & $33.8 \%$ & $46.0 \%$ & $43.0 \%$ & $40.9 \%$ & $38.1 \%$ \\
\hline $\mathrm{CI}$ & $22.9-46.8$ & $27.8-65.3$ & $23.9-64.5$ & $20.9-64.4$ & $29.4-47.6$ \\
\hline No & $22.6 \%$ & $8.3 \%$ & $25.9 \%$ & $8.3 \%$ & $20.1 \%$ \\
\hline $\mathrm{CI}$ & $13.5-35.5$ & $3.3-19.5$ & $12.7-45.8$ & $3.3-19.0$ & $13.8-28.4$ \\
\hline Not sure & $43.5 \%$ & $45.7 \%$ & $31.0 \%$ & $50.9 \%$ & $41.8 \%$ \\
\hline CI & $30.5-57.5$ & $27.4-65.1$ & $14.5-54.5$ & $29.4-72.0$ & $32.5-51.7$ \\
\hline
\end{tabular}

How likely would marry current same-sex partner, if legal? ${ }^{\mathrm{d}}$ (Respondents currently in a same-sex relationship) ${ }^{\mathrm{e}}$
Not at all likely
$21.6 \%$
$11.5 \%$
CI
13.3-33.2
5.9-21.1
Somewhat likely
$37.7 \%$ a
$12.2 \% \mathrm{~b}$
CI
26.3-50.6
6.8-20.8
Fairly likely or very likely
$40.7 \%$ a $\quad 76.4 \%$ b
CI
$29.8-52.5$
65.6-84.5 
Table 8 (continued)

\begin{tabular}{|c|c|c|c|c|c|}
\hline Variable & Gay men & Lesbians & Bisexual men & Bisexual women ${ }^{a}$ & Total \\
\hline \multicolumn{6}{|l|}{ Parental status } \\
\hline No children & $91.6 \% \mathrm{a}$ & $65.1 \% \mathrm{~b}$ & $63.5 \%$ bc & $32.8 \% \mathrm{c}$ & $66.2 \%$ \\
\hline $\mathrm{CI}$ & $87.1-94.6$ & $54.9-74.1$ & $42.1-80.7$ & $23.6-43.5$ & $59.1-72.7$ \\
\hline 1 child & $3.3 \% \mathrm{a}$ & $15.7 \% \mathrm{~b}$ & $8.4 \% \mathrm{ab}$ & $27.5 \% \mathrm{~b}$ & $12.2 \%$ \\
\hline CI & $1.5-7.1$ & $10.2-23.3$ & $3.6-18.5$ & $17.2-40.8$ & $8.7-16.9$ \\
\hline $2+$ children & $5.1 \% \mathrm{a}$ & $19.3 \% \mathrm{~b}$ & $28.0 \%$ bc & $39.7 \% \mathrm{c}$ & $21.5 \%$ \\
\hline CI & $3.0-8.5$ & $12.0-29.4$ & $12.8-50.9$ & $29.4-51.1$ & $15.9-28.4$ \\
\hline
\end{tabular}

Within rows, values with different lowercase letters differ significantly, as indicated by nonoverlapping confidence intervals. $*=$ results not reported because of the small number of bisexuals in a same-sex relationship

${ }^{a}$ Two bisexual women reported that they were cohabiting but did not report the gender of their partner; they are excluded from the "Relationship Status" section of the table

${ }^{\mathrm{b}}$ Includes four lesbians and four gay men who reported they were in a cohabiting relationship but did not report the gender of their partner, as well as one lesbian and one bisexual woman who characterized their cohabiting partner as transgender

${ }^{\mathrm{c}}$ Includes two lesbians and three gay men who did not report their current relationship status but reported elsewhere in the questionnaire that they were legally single or divorced

${ }^{\mathrm{d}}$ For Massachusetts residents, the clause "if same-sex marriages were legally recognized in your state" was not included in the question

${ }^{\mathrm{e}}$ Because of the small number of bisexual men and women in a same-sex relationship, responses are reported only for gay men and lesbians

and bisexual women $(M=1.46, \mathrm{CI}=1.11-1.82)$ was reliable. Lesbians $(M=1.93, \mathrm{CI}=1.62-2.25)$ scored between the two, and bisexual men scored the lowest, albeit with the largest CI $(M=1.34, \mathrm{CI}=0.64-2.05)$.

\section{Religious and Political Characteristics}

As shown in Table 6, more than half of the respondents belonged to a Christian denomination, and most of these were Catholics $(20 \%)$ or Protestants who reported they were not born again Christians (30\%). However, slightly more than one respondent in six reported being born again. Roughly $3 \%$ reported they were Wiccan or pagan, and about the same proportion were Buddhist. About 1\% were Jewish. Nearly one respondent in four was an atheist or agnostic or reported having no religion.

Across sexual orientation subgroups, the distributions among religious denominations, attendance at religious services, and proportion of sexual-minority members in one's congregation did not differ significantly. However, with age, education, and race statistically controlled, lesbians and bisexual men reported receiving significantly more daily guidance from their religion, compared with gay men and bisexual women. With religious guidance expressed as a score on a 4-point scale $(1=$ none at all, $4=$ a great deal of guidance), lesbians' and bisexual men's mean scores were 2.22 and 2.42, respectively, compared with 1.96 for gay men and 1.97 for bisexual women (Table 6). Examination of the frequencies within each response category suggests that lesbians and bisexual men were somewhat more likely to report that religion offers them a great deal of guidance, whereas gay men and bisexual women were more likely to report receiving no guidance from religion.

However, in response to a follow-up question ("How important is spirituality in your life?"), roughly two thirds of the respondents who said they received no daily guidance from religion nevertheless assigned at least some importance to spirituality (not shown in Table 6). When these responses were combined with ratings of the importance of religion, the aforementioned group differences were eliminated. Only $10.6 \%$ of the sample reported both that they received no guidance from religion and that spirituality was "not at all important" to them $(\mathrm{CI}=7.6$ 14.7). A majority (51.8\%, CI=44.6-59.0) reported either that they received "some" guidance from religion or that spirituality was "not too important." Another $21.4 \%$ (CI= 16.7-26.9) received "quite a bit" of guidance or considered spirituality to be "somewhat important," and 16.2\% (CI= 10.4-24.5) received "a great deal" of guidance or considered spirituality to be "very important."

As reported in Table 7, the sample largely identified as Democratic, tended to be politically liberal, and overwhelmingly reported having voted for John Kerry in the 2004 presidential election. These patterns are consistent with findings from previous studies that gay, lesbian, and bisexual voters are less conservative than the general voting 
public (e.g., Edelman 1993; Hertzog 1996). Except for the fact that no lesbians reported having voted for Ralph Nader, the subgroups did not differ significantly on these variables.

\section{Relationship and Family Characteristics}

Women were significantly more likely than men to report they were currently in a committed relationship, either heterosexual or homosexual. As shown in Table $8,60 \%$ of gay men and $57 \%$ of bisexual men were not in a committed relationship, compared with fewer than one fourth of lesbians and bisexual women. Another notable difference was observed between homosexual and bisexual respondents: Whereas all coupled lesbians and virtually all coupled gay men reported that their partner was someone of their same sex, the vast majority of coupled bisexual men (88\%) and women $(90 \%)$ had a different-sex partner.

Most uncoupled respondents either stated they would like to marry someday or indicated uncertainty about it; overall, only $20 \%$ expressed no interest in ever marrying. Among respondents who were currently in a same-sex relationship, significantly more lesbians than gay men said they were "very likely" or "fairly likely" to marry their partner ( $76 \%$ and $41 \%$, respectively), whereas more gay men than lesbians said they were "somewhat likely" to marry (38\% and $12 \%$, respectively). In all, nearly $90 \%$ of lesbians and $80 \%$ of gay men indicated some likelihood of marrying their current partner. (Because so few bisexuals were in a same-sex relationship, their responses to this question are not reported.)

Overall, approximately one third of respondents reported having one or more children, including adopted and stepchildren. Gay men were the least likely to have a child $(8 \%)$, whereas approximately two thirds of bisexual women reported having one or more children. About one third of lesbians and bisexual men reported having children.

Respondents overwhelmingly supported legal recognition for same-sex couples. Although bisexual males were somewhat less supportive than others, the overlapping confidence intervals across groups indicate that these differences were not reliable. Overall, $77.9 \%$ of respondents $(\mathrm{CI}=69.7-84.4)$ agreed that "The law should allow two people of the same sex to marry each other," whereas $74.4 \%(\mathrm{CI}=66.4-81.1)$ disagreed with the assertion that "There is really no need to legalize same-sex marriage in the United States." Similarly, 89.1\% (CI=81.2-93.9) supported civil unions. The sample was divided in its response to the statement "The U.S. public isn't ready for a debate about gay marriage." A plurality $(42 \%, \mathrm{CI}=35.1-$ $49.2)$ disagreed, but $28.1 \%(\mathrm{CI}=23.0-33.9)$ agreed, and $29.9 \%(\mathrm{CI}=22.9-38.1)$ placed themselves "in the middle" between agreement and disagreement.

\section{Discussion}

The data presented here offer a wealth of information about the general characteristics of self-identified gay, lesbian, and bisexual adults in the USA while highlighting important commonalities and differences among sexual orientation subgroups. Without recapitulating all of the results, we comment here on some key findings.

To begin, the composition of the sample is noteworthy. With design weights applied to account for aspects of the sampling procedures that might have affected respondents' likelihood of inclusion in the $\mathrm{KN}$ panel, fully half of the participants identified as bisexual, indicating that bisexuals constitute a substantial portion of the self-identified sexualminority population. In addition, gay men outnumbered lesbians at a ratio of approximately $2.4: 1$. This finding is consistent with data from other national probability samples (Black et al. 2000; Laumann et al. 1994) and suggests that self-identified gay men may outnumber self-identified lesbians in the US adult population. Among self-identified bisexuals, by contrast, the weighted proportions of women and men did not differ significantly. Within genders, the weighted sample included more gay than bisexual men and more bisexual women than lesbians, but the difference was reliable only among the women respondents. Of course, any inferences from these patterns about the composition of the sexual-minority population must be considered tentative until more data are obtained from other probability samples.

Sexual orientation and gender subgroups within the sample differed on key demographic variables, with bisexuals tending to be younger than homosexuals, and bisexual men the least likely to be non-Hispanic White or to have a college degree. Comparisons to the US adult population using contemporaneous Census data suggest that lesbians and bisexuals (but not gay men) may be younger, on average, than the US adult population; that bisexual men (but not lesbians, gay men, or bisexual women) may be less likely to be non-Hispanic White; and that lesbians and gay men (but not bisexuals) may be more highly educated. These patterns are consistent with previous findings from nonprobability samples indicating that lesbians and gay men tend to be highly educated (e.g., Herek et al. 1999; Rostosky et al. 2009; Rothblum and Factor 2001). They are also consistent with past observations that bisexual behavior is more common among African American and Latino men than among nonHispanic White males (e.g., Millett et al. 2005; O'Leary et al. 2007; Rust 2000).

Bisexual men and women were not only younger than the US adult population, they were also significantly younger than lesbians and gay men. This age difference might reflect generational differences in patterns of identity 
labeling: Perhaps younger people are more likely than their older counterparts to view their own sexuality in fluid terms and thus to identify as bisexual rather than exclusively homosexual or heterosexual. Alternatively, it could reflect developmental differences insofar as some younger respondents who currently self-identify as bisexual might later identify as gay or heterosexual (indeed, roughly one fifth of bisexual men and one tenth of bisexual women said they label themselves Gay or Lesbian at least some of the time). These accounts are not mutually exclusive. Younger adults may be more open to a bisexual identity today than was the case a generation ago, and bisexuality may constitute a transitional identity for some individuals who will ultimately define their sexuality in terms of exclusive attraction to men or women. Indeed, the findings of the present study suggest that bisexuals may constitute a more heterogeneous population than gay men and lesbians, one that includes not only individuals who publicly identify as bisexual but also those who privately acknowledge samesex attractions while currently maintaining a heterosexual relationship, and still others who are in the process of defining their sexuality. It is possible that comparisons of self-identified bisexual men and women according to their self-reported attraction patterns (i.e., mainly attracted to men, mainly attracted to women, equally attracted to both sexes) would yield useful insights in this regard. However, the present sample was not large enough to permit such analyses.

Compared with bisexual men and women, gay men and lesbians were more strongly committed to a minority sexual identity, identified more strongly with a sexual-minority community, were more likely to consider their community membership to be a reflection of themselves, and were generally more open about their sexual orientation. Overall, gay men and lesbians tended to attach greater importance than bisexuals to community involvement and were more likely to engage in such behaviors as attending rallies and demonstrations or donating money to community organizations. Here again, the present data suggest that the population of individuals who label themselves bisexual may be a more diverse group than those who self-identify as lesbian or gay and may include many women and men for whom being bisexual is not a primary basis for a personal identity or community involvement. These patterns may also reflect, in part, bisexuals' sometimes marginal status in established gay and lesbian communities, along with the relative lack of visible bisexual communities, owing to bisexuality's recent emergence as a public identity linked to a social movement (Herdt 2001; UdisKessler 1995).

Related to this point, substantial minorities of the bisexual respondents said they never $(4.6 \%$ of bisexual women, $8.1 \%$ of bisexual men) or rarely $(34.9 \%$ and $20.7 \%$, respectively) used Bisexual as a self-descriptor. By contrast, men who indicated they were homosexual overwhelmingly reported using the term Gay to describe themselves at least some of the time. Similarly, about three fourths of homosexual women used Lesbian as a self-label, and roughly the same proportion employed Gay as a selfdescriptor. The latter finding is somewhat surprising because Gay has often been assumed to be primarily a male-oriented identity label (e.g., Kulick 2000).

Other patterns of self-labeling also warrant comment. The term Queer was used by only a small minority of respondents, as was the case for Dyke among female respondents. Considerably more respondents (more than one third of gay men and lesbians) used Homosexual as a self-descriptor at least some of the time. Notably, gay male and lesbian respondents were much more likely to say they never used Queer as a self-descriptor $(58.9 \%$ of gay men, $65 \%$ of lesbians) than to say they never used Homosexual (32\% and $34.1 \%$, respectively). Bisexuals, by contrast, were about equally likely to say they never used either term. Among bisexual men, $71.7 \%$ never used Homosexual and $77.9 \%$ never used Queer; for bisexual women, the proportions were $88.8 \%$ and $87.3 \%$, respectively. Thus, although Queer has sometimes been suggested as an inclusive label for sexual minorities (e.g., Jacobs 1998), it appears that a majority of US gay, lesbian, and bisexual adults never used it to describe themselves at the time the survey was conducted.

Some recent court cases addressing rights for gay, lesbian, and bisexual people have considered questions related to the origins of sexual orientation and its mutability (e.g., In re Marriage Cases 2008; Varnum v. Brien 2009). Moreover, some opponents of equal rights for sexual minorities have asserted that homosexuality represents a willful choice of a sinful way of life (Herman 1997). ${ }^{12}$ In this context, it is noteworthy that most respondents in the present study-including bisexual men and womenreported that they experienced little or no choice about their sexual orientation. The question of exactly what is meant by "choice" in this realm warrants further discussion and research (see, for example, Whisman 1996), but if one's sexual orientation were experienced as a choice, it seems reasonable to expect that large numbers of gay, lesbian, and bisexual people would report this perception in response to a survey question.

We believe that the responses to this question may also provide a useful insight for interpreting the often observed correlation between heterosexuals' levels of sexual prejudice and their beliefs about whether homosexuality is a choice (e.g., Haider-Markel and Joslyn 2008; Hegarty

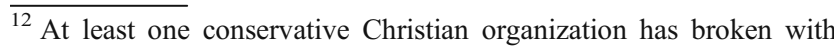
this position, stating on its website that "[w]e do not believe anyone chooses his or her same-sex attractions" (Love Won Out 2008).
} 
2002). If, as the present data indicate, gay, lesbian, and bisexual people experience little or no choice about their sexual orientation, they probably communicate this fact to their heterosexual friends and relatives. Given the consistently high correlations observed between heterosexuals' attitudes toward sexual minorities and the extent of their personal relationships with nonheterosexual individuals (Herek and Capitanio 1996; Lewis 2008; Pettigrew and Tropp 2006), the correlation that is reliably observed between origin beliefs and attitudes may result at least in part from both variables' association with personal contact.

Related to this point, the data reveal notable differences in disclosure and outness between gay men and lesbians, on the one hand, and bisexuals, on the other. The parents and siblings of gay men and lesbians are substantially more likely to know about the latter's sexual orientation than is the case for the families of bisexual men and women. A similar pattern was also observed in most categories of friends, other family, and coworkers: Compared with lesbians and gay men, significantly fewer bisexualsespecially men-reported they were out of the closet to even one member of these groups. Coming out as bisexual may differ in important respects from coming out as a gay or lesbian person (McLean 2007). Nevertheless, insofar as heterosexuals' levels of sexual prejudice are reduced by having personal relationships with nonheterosexuals (Herek and Capitanio 1996; Lewis 2008; Pettigrew and Tropp 2006), these patterns could have important implications for societal attitudes toward bisexual men and women.

The data indicate that self-identified gay, lesbian, and bisexual adults tend to be less religious and more politically liberal than the US population. Although most respondents reported that religion or spirituality provides some guidance in their daily lives, the sample overall reported a fairly low level of religious commitment. Slightly more than one fourth stated that they receive "quite a bit" or "a great deal" of guidance from religion in their daily lives, and this proportion increased to approximately $38 \%$ when the question was expanded to include spirituality as well as formal religion. By comparison, in the 2004 American National Election Survey (ANES), 35\% of US adults reported that religion provides a great deal of guidance in their day-to-day lives, and another $24 \%$ said it provides quite a bit of guidance. ${ }^{13}$ Whereas about one fourth of the present sample reported at least monthly attendance at religious services, a 2008 Pew survey found that $39 \%$ of Americans reported at least weekly attendance at religious

\footnotetext{
${ }^{13}$ The figures are based on our analysis of the 2004 National Election Study pre-election interview data, using the UC Berkeley SDA interface (http://sda.berkeley.edu/archive.htm).
}

worship services (Pew Forum on Religion and Public Life 2008).

The data corroborate previous findings that sexual minorities constitute a politically progressive constituency (e.g., Edelman 1993; Hertzog 1996; Schaffner and Senic 2006). A majority of respondents described themselves as liberal, and the sample was overwhelmingly Democratic in party affiliation and voting patterns. By comparison, $25 \%$ of the 2004 ANES respondents said they were liberal, and 32\% identified as Democrats, whereas a plurality (about 41\%) described themselves as conservative and $29 \%$ identified as Republicans.

Consistent with findings from previous research with convenience samples (Peplau and Fingerhut 2007), sexualminority women were substantially more likely than sexual-minority men to report that they were currently in a committed relationship. Whereas virtually all coupled gay men and lesbians had a same-sex partner, the vast majority of coupled bisexuals were in a heterosexual relationship. This disproportionate number of differentsex couples among bisexual adults probably has multiple explanations. In part, it may simply reflect the fact that most adults are heterosexual, and thus, bisexuals have many more opportunities to form a different-sex intimate relationship than a same-sex relationship. In addition, same-sex relationships are stigmatized and lack widespread legal recognition in the USA, whereas different-sex relationships enjoy social approval and many tangible benefits (Herek 2006). These factors may facilitate different-sex relationships among those bisexuals who are attracted to the other sex at least as much as to their own sex (roughly three fourths of the bisexual respondents in the present sample).

Among respondents who were not currently in a committed relationship, relatively few said they would not want to marry someday. A plurality, however, indicated uncertainty about the desirability of marrying. Among the homosexual respondents currently in a relationship, lesbians were substantially more likely than gay men to say they would be "very likely" or "fairly likely" to marry their current partner if they could legally do so ( $76 \%$ vs $41 \%)$. This pattern is consistent with the available data concerning patterns of marriage and registrations of civil unions and domestic partnerships, which reveal that female couples are considerably more likely than male couples to formally register their relationship when the law allows them to do so (Korber and Calvan 2008; Rothblum et al. 2008). It is also consistent with the present finding that lesbians are significantly more likely than gay men to live in a household with at least one other adult. Lesbians' greater tendency to seek legal recognition of their relationships may be explained in part by the fact that they are about four times more likely than gay men to have one or more 
children or to report that they have children younger than 18 years residing in their home. Seeking legal protections and benefits for children may be an important motivator for marrying (Herek 2006).

The data obtained in any survey are subject to possible error due to sampling, telephone noncoverage, and problems with question wording. In addition to these sources of error, we note several important limitations of the present study that should be kept in mind when interpreting the results. Our operationalization of sexual orientation in terms of identity means that the findings reported here should not be generalized to the population of US adults who experience same-sex attractions or have engaged in samesex sexual behavior but do not identify as lesbian, gay, or bisexual. The sample was restricted to English-speaking adults in households with a telephone; thus, it is potentially problematic to generalize from these results to non-English speakers, nonadults, and individuals without a telephone.

In addition, it is likely that some lesbian, gay, and bisexual adults in the full $\mathrm{KN}$ panel did not report their true sexual orientation in response to the original screening question and thus had no opportunity of being included in the present sample. Insofar as self-administered Internet questionnaires appear to elicit greater disclosure of sensitive and potentially stigmatizing information than telephone and face-to-face interviews (e.g., Kreuter et al. 2008), such underreporting may be less common in the $\mathrm{KN}$ panel than in surveys using other modes of data collection. Without minimizing the possibility of problems created by such nonreporting in the present study, we note that many respondents who had not disclosed their sexual orientation to their family or friends nevertheless reported it in the questionnaire.

Another potential limitation results from the fact that the data are derived from self-reports. As in any survey study, some respondents may have provided inaccurate responses to questions, either intentionally (e.g., because of social desirability concerns) or because of problems with comprehension or recall (Tourangeau et al. 2000). Yet another potential concern is whether the survey responses obtained from experienced Internet panel members might differ from those of naïve or "fresh" respondents. To date, the minimal research that has addressed this issue suggests that the response patterns of the two groups probably do not differ substantially (Toepoel et al. 2009). Finally, as with all surveys, the data represent a snapshot of the population at the time the study was fielded. Additional research with comparable probability samples will be needed to develop a more definitive portrait of sexual-minority adults in the USA. Such research will be useful not only in assessing the extent to which the findings of the present study can be reliably replicated but also might permit more detailed analyses of key subgroups within the sexual-minority population. It would be illuminating, for example, to compare lesbian, gay, and bisexual adults in different race and ethnic groups on many of the variables discussed previously. In the present sample, these subgroups are too small for reliable analyses.

Throughout the present article, we have noted the importance of having accurate data about gay, lesbian, and bisexual people for legal and policy debates. Such information will also be highly useful for informing behavioral and social science research on sexual orientation and sexual minorities in a variety of ways. In particular, the present findings highlight the importance for researchers of distinguishing among lesbian, gay, bisexual female, and bisexual male individuals, rather than combining them into an undifferentiated "LGB" group. For example, the data indicate that sexual orientation groups differ in their levels of identity commitment, community involvement, and outness. Future research might profitably examine whether the meanings attached to these and related variables - and, indeed, the very concept of community membership_-might differ among sexual orientation subgroups.

Moreover, because these variables may play important roles in moderating the effects of sexual stigma on psychological well-being (Herek and Garnets 2007; Meyer 2003), studies of sexual-minority mental health should include separate analyses of bisexuals and homosexuals, as well as of men and women. A similar analytic strategy should be followed in studies of intimate relationships among sexual minorities because, as shown here, sexual orientation and gender groups differ significantly in their relationship patterns. More broadly, the present study demonstrates the need for researchers to conceive of gay men, lesbians, bisexual men, and bisexual women not only as a cultural minority united by the common experience of sexual stigma but also as distinct groups whose members have different experiences, beliefs, and needs.

As society confronts a widening array of policy issues that uniquely affect sexual minorities, accurate scientific information about the lesbian, gay, and bisexual population will continue to be needed by government officials, the courts, and legislative bodies. Social and behavioral researchers working in this area have long recognized the value of data collected through probability sampling methods and have used a variety of creative strategies during the past two decades to obtain such data. In reporting what is perhaps the most extensive description to date of a national probability sample of self-identified lesbian, gay, and bisexual adults in the USA, the present article extends these efforts. We hope it will be useful not only for informing policy but also for generating hypotheses that can be tested in future studies with ever more sophisticated samples. 
Acknowledgments Data collection was funded by a grant to Gregory Herek from the Gill Foundation. Throughout the project, we received assistance, feedback, and helpful suggestions from a large number of colleagues - too many to list here. We express our appreciation to all of them and our special thanks to Lee Badgett, Aaron Belkin, Murray Edelman, Gary Gates, Ethan Geto, Jeff Henne, Anne Peplau, and Ken Sherrill. We also thank Clinton Anderson and Linda Garnets for their helpful comments on an earlier draft of this article.

Open Access This article is distributed under the terms of the Creative Commons Attribution Noncommercial License which permits any noncommercial use, distribution, and reproduction in any medium, provided the original author(s) and source are credited.

\section{References}

American Association for Public Opinion Research. (2006). Standard definitions: Final dispositions of case codes and outcome rates for surveys. Lenexa, KS: Author.

American Psychological Association. (1986). Bowers v. Hardwick: Brief for amicus curiae, Supreme Court of the United States. Washington, DC: Author.

American Psychological Association. (2003). Lawrence v. Texas: Brief for amicus curiae, Supreme Court of the United States. Washington, DC: Author.

American Psychological Association. (2007). In re marriage cases: Brief for amicus curiae, California Supreme Court. Washington, DC: Author

Badgett, M. V. L. (1995). The wage effects of sexual orientation discrimination. Industrial \& Labor Relations Review, 48, 726-739.

Balsam, K. F., \& Mohr, J. J. (2007). Adaptation to sexual orientation stigma: A comparison of bisexual and lesbian/gay adults. Journal of Counseling Psychology, 54, 306-319.

Balsam, K. F., Beauchaine, T. P., Rothblum, E. D., \& Solomon, S. E. (2008). Three-year follow-up of same-sex couples who had civil unions in Vermont, same-sex couples not in civil unions, and heterosexual married couples. Developmental Psychology, 44, 102116.

Belkin, A. (2008). "Don't ask, don't tell": Does the gay ban undermine the military's reputation? Armed Forces \& Society, 34, 276-291.

Bell, A. P., \& Weinberg, T. S. (1978). Homosexualities: A study of diversity among men and women. New York: Simon \& Schuster.

Berg, N., \& Lien, D. (2002). Measuring the effect of sexual orientation on income: Evidence of discrimination? Contemporary Economic Policy, 20, 394-414.

Berrens, R. P., Bohara, A. K., Jenkins-Smith, H., Silva, C., \& Weimer, D. L. (2003). The advent of Internet surveys for political research: A comparison of telephone and Internet samples. Political Analysis, 11, 1-22.

Black, D., Gates, G., Sanders, S., \& Taylor, L. (2000). Demographics of the gay and lesbian population in the United States: Evidence from available systematic data sources. Demography, 37, 139154

Black, D., Gates, G., Sanders, S., \& Taylor, L. (2003). The measurement of same-sex unmarried partner couples in the 2000 U.S. Census. Paper presented at the meeting of the Population Association of America, Minneapolis, MN.

Black, D., Gates, G., Sanders, S., \& Taylor, L. (2007). The measurement of unmarried partner couples in the 2000 U.S. Census (On-line working paper CCPR-023-07). Los Angeles: California Center for Population Research. http://www.ccpr.ucla. edu/ccprwpseries/ccpr_023 07.pdf. Accessed 7 Sept 2007.
Blair, J. (1999). A probability sample of gay urban males: The use of twophase adaptive sampling. Journal of Sex Research, 36, 39-44.

Blandford, J. M. (2003). The nexus of sexual orientation and gender in the determination of earnings. Industrial \& Labor Relations Review, 56, 622-642.

Bradford, J., Ryan, C., \& Rothblum, E. D. (1994). National Lesbian Health Care Survey: Implications for mental health care. Journal of Consulting and Clinical Psychology, 62, 228-242.

Carpenter, C. S. (2005). Self-reported sexual orientation and earnings: Evidence from California. Industrial \& Labor Relations Review, $58,258-273$.

Chang, L., \& Krosnick, J. A. (2009). National surveys via RDD telephone interviewing vs. the Internet: Comparing sample representativeness and response quality. Public Opinion Quarterly, 73, 641-678.

Cochran, S. D., \& Mays, V. M. (2000). Lifetime prevalence of suicide symptoms and affective disorders among men reporting same-sex sexual partners: Results from NHANES III. American Journal of Public Health, 90, 573-578.

Cochran, S. D., \& Mays, V. M. (2006). Estimating prevalence of mental and substance-using disorders among lesbians and gay men from existing national health data. In A. M. Omoto \& H. S. Kurtzman (Eds.), Sexual orientation and mental health: Examining identity and development in lesbian, gay, and bisexual people (pp. 143-165). Washington, DC: American Psychological Association.

Cumming, G. (2008). Replication and $p$ intervals: $p$ values predict the future only vaguely, but confidence intervals do much better. Perspectives on Psychological Science, 3, 286-300.

Diaz, R. M., Stall, R. D., Hoff, C., Daigle, D., \& Coates, T. J. (1996). HIV risk among Latino gay men in the southwestern United States. AIDS Education and Prevention, 8, 415-429.

Diaz, R. M., Ayala, G., \& Bein, E. (2004). Sexual risk as an outcome of social oppression: Data from a probability sample of Latino gay men in three U.S. cities. Cultural Diversity and Ethnic Minority Psychology, 10, 255-267.

Edelman, M. (1993). Understanding the gay and lesbian vote in ' 92. The Public Perspective, 4(3), 32-33.

Egan, P. J., \& Sherrill, K. (2005). Marriage and the shifting priorities of a new generation of lesbians and gays. PS: Political Science \& Politics, 38, 229-232.

Haider-Markel, D. P., \& Joslyn, M. R. (2008). Beliefs about the origins of homosexuality and support for gay rights: An empirical test of attribution theory. Public Opinion Quarterly, 72, 291-310.

Harry, J. (1986). Sampling gay men. Journal of Sex Research, 22, 21-34.

Harry, J. (1990). A probability sample of gay males. Journal of Homosexuality, 19(1), 89-104.

Hegarty, P. (2002). "It's not a choice, it's the way we're built": Symbolic beliefs about sexual orientation in the US and Britain. Journal of Community \& Applied Social Psychology, 12, 153-166.

Herdt, G. H. (2001). Social change, sexual diversity, and tolerance for bisexuality in the United States. In A. R. D'Augelli \& C. J. Patterson (Eds.), Lesbian, gay, and bisexual identities and youth: Psychological perspectives (pp. 267-283). New York: Oxford University Press.

Herek, G. M. (2000). Homosexuality. In A. E. Kazdin (Ed.), Encyclopedia of psychology (Vol. 4, pp. 149-153). Washington, DC: American Psychological Association.

Herek, G. M. (2006). Legal recognition of same-sex relationships in the United States: A social science perspective. American Psychologist, 61, 607-621.

Herek, G. M. (2009a). Hate crimes and stigma-related experiences among sexual minority adults in the United States: Prevalence estimates from a national probability sample. Journal of Interpersonal Violence, 24, 54-74. 
Herek, G. M. (2009b). Sexual stigma and sexual prejudice in the United States: A conceptual framework. In D. A. Hope (Ed.), Contemporary perspectives on lesbian, gay and bisexual identities: The 54th Nebraska Symposium on Motivation (pp. 65-111). New York: Springer.

Herek, G. M., \& Capitanio, J. P. (1996). "Some of my best friends": Intergroup contact, concealable stigma, and heterosexuals' attitudes toward gay men and lesbians. Personality and Social Psychology Bulletin, 22, 412-424.

Herek, G. M., \& Garnets, L. D. (2007). Sexual orientation and mental health. Annual Review of Clinical Psychology, 3, 353-375.

Herek, G. M., \& Glunt, E. K. (1995). Identity and community among gay and bisexual men in the AIDS era: Preliminary findings from the Sacramento Men's Health Study. In G. M. Herek \& B. Greene (Eds.), AIDS, identity, and community: The HIV epidemic and lesbians and gay men (pp. 55-84). Thousand Oaks: Sage.

Herek, G. M., Cogan, J. C., Gillis, J. R., \& Glunt, E. K. (1998). Correlates of internalized homophobia in a community sample of lesbians and gay men. Journal of the Gay and Lesbian Medical Association, 2, 17-25.

Herek, G. M., Gillis, J. R., \& Cogan, J. C. (1999). Psychological sequelae of hate-crime victimization among lesbian, gay, and bisexual adults. Journal of Consulting and Clinical Psychology, 67, 945-951.

Herek, G. M., Chopp, R., \& Strohl, D. (2007). Sexual stigma: Putting sexual minority health issues in context. In I. Meyer \& M. Northridge (Eds.), The health of sexual minorities: Public health perspectives on lesbian, gay, bisexual, and transgender populations (pp. 171-208). New York: Springer.

Herek, G. M., Gillis, J. R., \& Cogan, J. C. (2009). Internalized stigma among sexual minority adults: Insights from a social psychological perspective. Journal of Counseling Psychology, 56, 32-43.

Herman, D. (1997). The antigay agenda: Orthodox vision and the Christian right. Chicago: University of Chicago Press.

Hertzog, M. (1996). The lavender vote: Lesbians, gay men, and bisexuals in American electoral politics. New York: New York University Press.

Holbrook, A. L., Krosnick, J. A., \& Pfent, A. (2008). The causes and consequences of response rates in surveys by the news media and government contractor survey research firms. In J. Lepkowski, C. Tucker, J. M. Brick, E. de Leeuw, L. Japec, P. J. Lavrakas, et al. (Eds.), Advances in telephone survey methodology (pp. 499528). New York: Wiley.

In re Marriage Cases, 183 P.3d 384, 76 Cal. Rptr. 3d 683 (2008).

Jacobs, G. (1998). The struggle over naming: A case study of "queer" in Toronto, 1990-1994. World Englishes, 17, 193-201.

Kish, L. (1965). Survey sampling. New York: Wiley.

Knowledge Networks. (2009). Knowledge Networks bibliography: Articles and presentations based on $\mathrm{KN}$ collected data, analysis, methodology. http://www.knowledgenetworks.com/ganp/. Accessed 26 March 2009.

Korber, D., \& Calvan, B. C. (2008). Female couples taking the lead in same-sex marriage. Sacramento Bee. http://www.sacbee.com/ 101/v-print/story/1027609.html. Accessed 20 June 2008.

Kreuter, F., Presser, S., \& Tourangeau, R. (2008). Social desirability bias in CATI, IVR, and Web Surveys: The effects of mode and question sensitivity. Public Opinion Quarterly, 72, 847865 .

Krosnick, J. A. (1991). Response strategies for coping with the cognitive demands of attitude measures in surveys. Applied Cognitive Psychology, 5, 213-236.

Kulick, D. (2000). Gay and lesbian language. Annual Review of Anthropology, 29, 243-285.
Laumann, E. O., Gagnon, J. H., Michael, R. T., \& Michaels, S. (1994). The social organization of sexuality: Sexual practices in the United States. Chicago: University of Chicago Press.

Lee, E. S., \& Forthofer, R. N. (2006). Analyzing complex survey data (2nd ed.). Thousand Oaks: Sage.

Lewis, G. B. (2008). The friends and family plan: Knowing LGBs and supporting gay rights Atlanta: Andrew Young School of Policy Studies Research Paper Series No. 07-10. http://ssrn.com/ abstract $=975975$ Accessed 4 February 2010.

Love Won Out. (2008). Frequently asked questions. http://www. lovewonout.com/questions/. Accessed 29 Aug 2009.

Luhtanen, R. K., \& Crocker, J. (1992). A collective self-esteem scale: Self-evaluation of one's social identity. Personality and Social Psychology Bulletin, 18, 302-318.

Martin, J. L., \& Dean, L. (1990). Developing a community sample of gay men for an epidemiologic study of AIDS. American Behavioral Scientist, 33, 546-561.

Mays, V. M., \& Cochran, S. D. (2001). Mental health correlates of perceived discrimination among lesbian, gay, and bisexual adults in the United States. American Journal of Public Health, 91, $1869-1876$.

McLean, K. (2007). Hiding in the closet? Bisexuals, coming out and the disclosure imperative. Journal of Sociology, 43, 151-166.

Meyer, I. H. (2003). Prejudice, social stress, and mental health in lesbian, gay, and bisexual populations: Conceptual issues and research evidence. Psychological Bulletin, 129, 674-697.

Meyer, I. H., \& Colten, M. E. (1999). Sampling gay men: Random digit dialing versus sources in the gay community. Journal of Homosexuality, 37(4), 99-110.

Meyer, I. H., \& Wilson, P. A. (2009). Sampling lesbian, gay, and bisexual populations. Journal of Counseling Psychology, 56, 23-31.

Millett, G., Malebranche, D., Mason, B., \& Spikes, P. (2005). Focusing "down low": Bisexual Black men, HIV risk and heterosexual transmission. Journal of the National Medical Association, 97, 52S-59S.

O'Leary, A., Fisher, H. H., Purcell, D. W., Spikes, P. S., \& Gomez, C. A. (2007). Correlates of risk patterns and race/ethnicity among HIV-positive men who have sex with men. AIDS and Behavior, 11, 706-715.

Peplau, L. A., \& Fingerhut, A. W. (2007). The close relationships of lesbians and gay men. Annual Review of Psychology, 58, 405-424.

Pettigrew, T. F., \& Tropp, L. R. (2006). A meta-analytic test of intergroup contact theory. Journal of Personality and Social Psychology, 90, 751-783.

Pew Forum on Religion and Public Life. (2008). U.S. religious landscape survey. http://religions.pewforum.org/pdf/report2religious-landscape-study-full.pdf. Accessed 23 June 2008.

Riggle, E. D., Rostosky, S. S., \& Reedy, C. S. (2005). Online surveys for BGLT research: Issues and techniques. Journal of Homosexuality, 49(2), 1-21.

Rodriguez, E. M., \& Ouellette, S. C. (2000). Gay and lesbian Christians: Homosexual and religious identity integration in the members and participants of a gay-positive church. Journal for the Scientific Study of Religion, 39, 333-347.

Rostosky, S. S., Riggle, E. D. B., Horne, S. G., \& Miller, A. D. (2009). Marriage amendments and psychological distress in lesbian, gay and bisexual (LGB) adults. Journal of Counseling Psychology, 56, 56-66.

Rothblum, E. D., \& Factor, R. (2001). Lesbians and their sisters as a control group: Demographic and mental health factors. Psychological Science, 12, 63-69.

Rothblum, E. D., Balsam, K. F., \& Mickey, R. M. (2004). Brothers and sisters of lesbians, gay men, and bisexuals as a demographic 
comparison group. Journal of Applied Behavioral Science, 40, 283-301.

Rothblum, E. D., Balsam, K. F., \& Solomon, S. E. (2008). Comparison of same-sex couples who were married in Massachusetts, had domestic partnerships in California, or had civil unions in Vermont. Journal of Family Issues, 29, 48-78.

Rust, P. C. (2000). Bisexuality in HIV research. In P. C. Rust (Ed.), Bisexuality in the United States: A social science reader (pp. 356-399). New York: Columbia University Press.

Schaffner, B., \& Senic, N. (2006). Rights or benefits? Explaining the sexual identity gap in American political behavior. Political Research Quarterly, 59, 123-132.

Sell, R. L. (2007). Defining and measuring sexual orientation for research. In I. H. Meyer \& M. E. Northridge (Eds.), The health of sexual minorities: Public health perspectives on lesbian, gay, bisexual, and transgender populations (pp. 355-374). New York: Springer.

Sell, R. L., \& Petrulio, C. (1996). Sampling homosexuals, bisexuals, gays, and lesbians for public health research: A review of the literature from 1990 to 1992. Journal of Homosexuality, 30(4), 31-47.

Sell, R. L., \& Silenzio, V. M. B. (2006). Lesbian, gay, bisexual, and transgender public health research. In M. D. Shankle (Ed.), The handbook of lesbian, gay, bisexual, and transgender public health (pp. 33-56). New York: Harrington Park Press.

Sell, R. L., Kates, J., \& Brodie, M. (2007). Use of a telephone screener to identify a probability sample of gays, lesbians, and bisexuals. Journal of Homosexuality, 53(4), 163-171.

Stall, R., \& Wiley, J. (1988). A comparison of alcohol and drug use patterns of homosexual and heterosexual men: The San Francisco Men's Health Study. Drug and Alcohol Dependence, 22, 63-73.

Toepoel, V., Das, M., \& Van Soest, A. (2009). Effects of design in web surveys: Comparing trained and fresh respondents. Public Opinion Quarterly, 72, 985-1007.

Tourangeau, R., Rips, L. J., \& Rasinski, K. A. (2000). The psychology of survey response. Cambridge: Cambridge University Press.

Udis-Kessler, A. (1995). Identity/politics: A history of the bisexual movement. In N. Tucker (Ed.), Bisexual politics: Theories, queries, and visions (pp. 17-30). New York: Haworth Press.

Varnum v. Brien, Iowa Sup. LEXIS 31 (2009).

Whisman, V. (1996). Queer by choice: Lesbians, gay men, and the politics of identity. New York: Routledge.

Wilkinson, L., \& Task Force on Statistical Inference. (1999). Statistical methods in psychology journals: Guidelines and explanations. American Psychologist, 54, 594-604. 